\title{
أثر دلالة النفي في الخلاف الفقهي تطبيقاً على قرائة الفاتحة في الصلاة
}

\author{
مستخلص من وسالتّ ماجستير بعنوان:

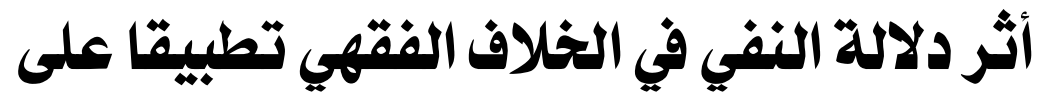

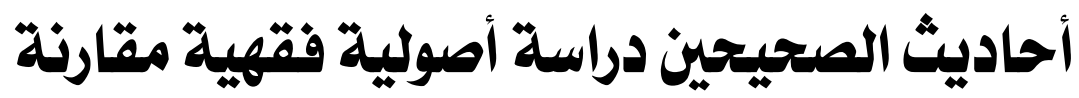

\author{
إعد اد \\ ياسمين هموم
}

المعيدة بقسم الشريعت الإسلاميتة

$$
\text { إشراف }
$$

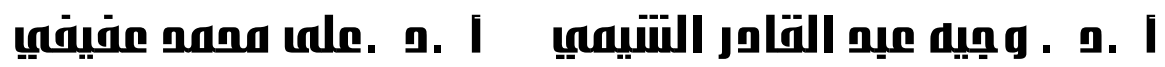
الأستاذ بقسه الشريعت الإسلاميت أستاذ ورئيس قسه, الشريعت الإسلاميت كليت دار العلوه - جامعت الفيوه 
أثر دلالة النفي في الخلاف الفقهي تطبيقاً على قراءة الفاتحة في الصلاة ــ

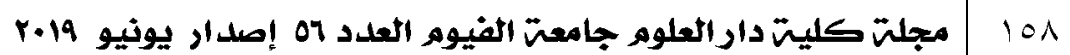




\section{أثر دلالة النفي في الخلاف الفقهي تطبيقاً على قراءة الفاتحة في الصلاة}

تناول البحث مفهوم النف عند اللغويين والأصوليين ، هو من الأسباب التي تؤدي الحلاف الفقهي فقد يدل النفي على نفي الأصل وأحيانيا يدل على نفي الكمال ،

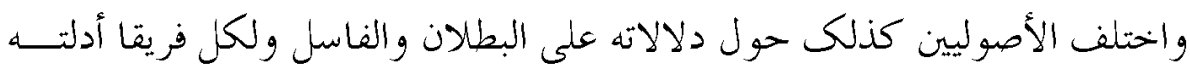
في ذلك منا يؤدي إلى كثر الحلاف في أبواب الفقه المختلفة منها مسألة قراءة الفاتحة في الصالاة

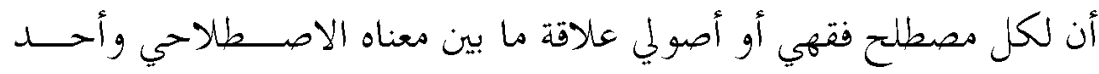

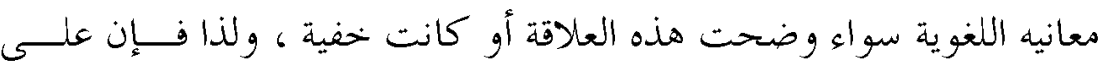
طالب العلم الشرعي أن يجمع بين العلوم الشرعية وعلوم اللغة العربية .

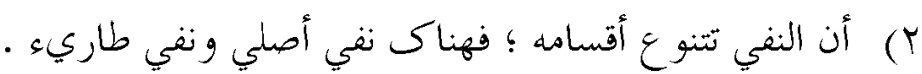

r) أن الأصل في اللغة العربية أن يكون مطلق النفي لنفي حقيقة وماهية الشيء، وأن صرف النفي على نفي الكمال يكون بحازاً .

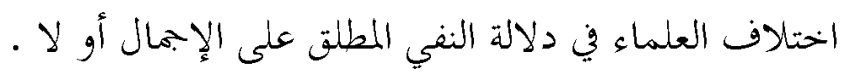

ه) اختلاف العلماء في إمكانية الاعتماد على النفي في تعليل الأحكام الشرعية . أن للنفي أثر واضح في اختلاف الفقهاء، ولكل فقيه وجهة نظره في الترجيح،

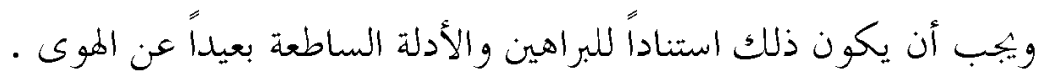
summary:

The research dealt with the concept of negation among linguists and fundamentalists, and it is one of the reasons that lead to jurisprudential disagreement. Negation may indicate the denial of the original and sometimes it indicates the denial of perfection, and the fundamentalists also differed about its implications for invalidity and failure, and each group has evidence in that, which leads to a lot of disagreement in the various chapters of jurisprudence, including The issue of reciting Al-Fatihah in prayer 
1) That every legal or fundamental term has a relationship between its idiomatic meaning and one of its linguistic meanings, whether this relationship is clear or hidden.

2)that negation has various types; There is an original denial and an emergency denial.

3) That the origin in the Arabic language is that an absolute negation is to deny the reality and essence of a thing, and that spending the negation on the negation of perfection is metaphorical.

4) Scholars differ as to the significance of the absolute negation in general or not.

5) Scholars differ in the possibility of relying on negation in justifying legal rulings.

6) The negation has a clear impact on the differences of jurists, and each jurist has his own opinion on the weighting, and this must be based on evidence and bright evidence away from whims. $\square$

\section{الكلمات الافتتاحية :}

نفي الصحة والكمال ، دلالات النفي على الفاسد أو الــبطلان، حكـــم قراءة الفاتحة في الصلاة

مقدمة فرامة

إن الحمد لله والصلاة والسلام على رسول الله سيدنا محمد وعلى آله وصحبه وسلم أما بعد :

إن للشارع الحكيم مناهج مختلفة وطرق متعددة في التعـبير عـن الأحكــام

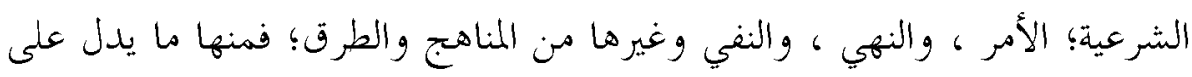

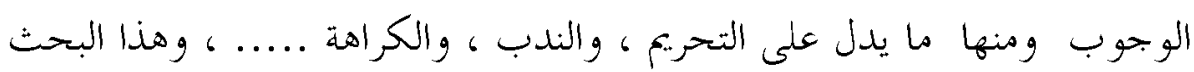

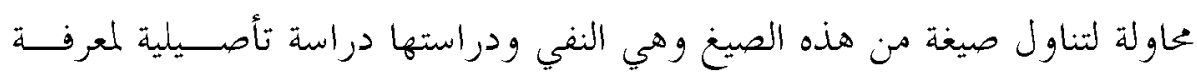

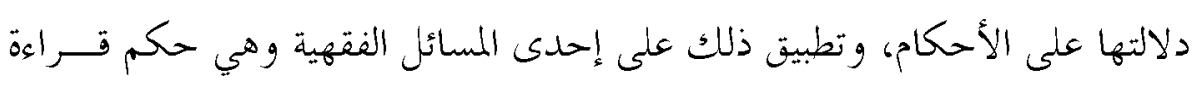
الفاتحة في الصلاة. 
مشكلة البحث :

تتمثل مشكلة البحث في النصوص الشرعية النافية ، وهل يلزم مــن النفــي

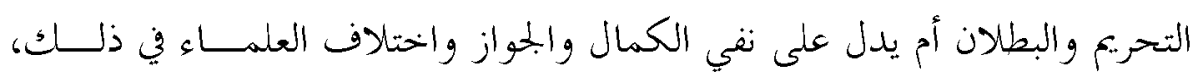

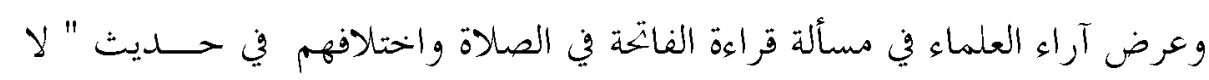

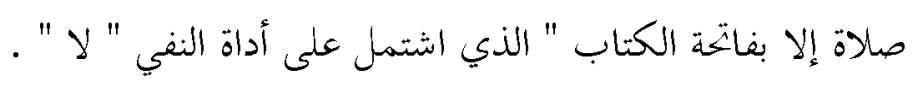
أهمية البحث : الاثة

تظهر أهمية البحث في أنه معاولة لمعالجة قضية أصولية تتعلق بأفعال المكلفــين

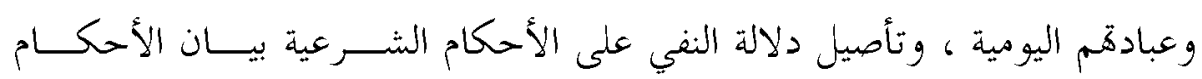

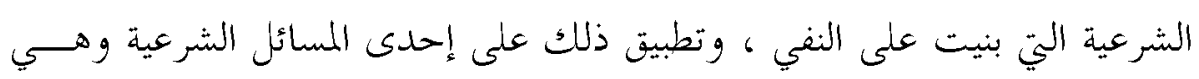

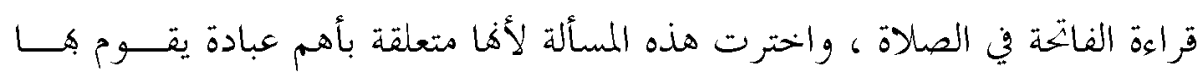

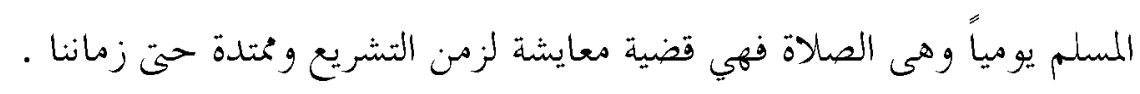

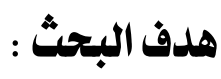

يهدف البحث إلى بيان دلالة النفي عن الأحكام الشرعية على نفي الصحة أو الو الو

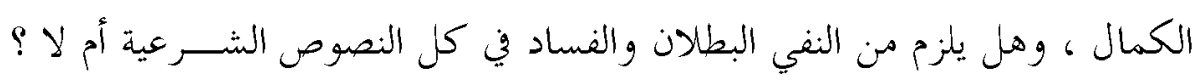

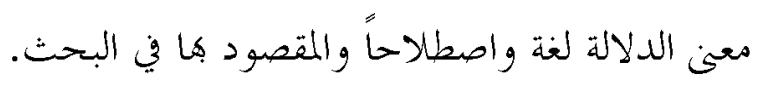

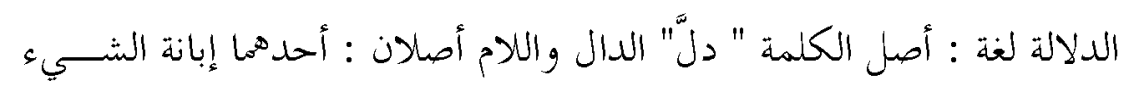

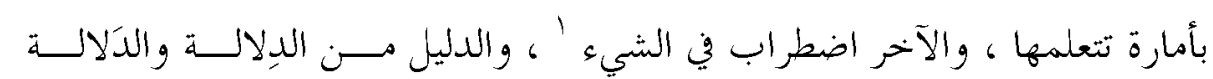

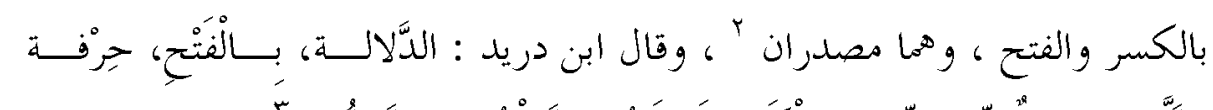

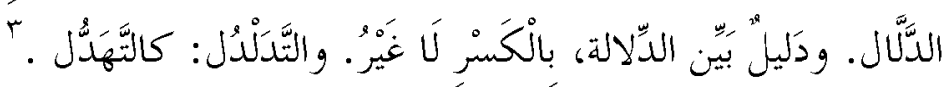

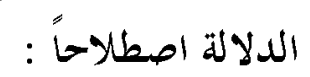

هي كون الشيء بحالة يلزم من العلم به العلم بشيء آخر، والشيء الأول هو هو الدال، والثاي هو المدلول . المبكي 
وأما عن المقصود بالدلالة في الدلالة موضوع البحث ، فهو دراسة الدلالات

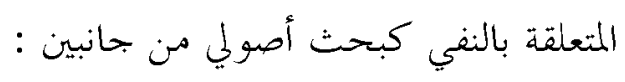

الأول : هو الجحانب الفقهي ، وتتعرض فيه الباحثة لدراسة دلالة النفي الدالة

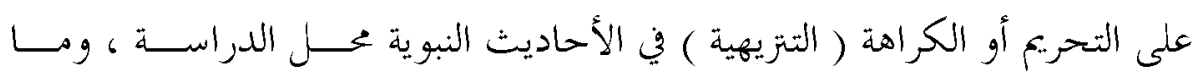
يترنب على ذلك من أحكام شرعية .

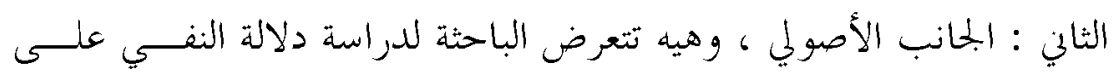

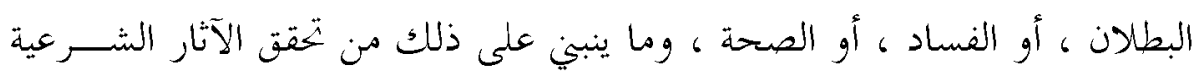

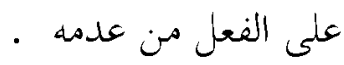
معنى النفي لخةً :

النون والفاء والحرف المعتل أصيل يدل على تعرية شيء من شيء وإبعاده منه، ونفيت الشيء نفياً وانتفى هو انتفاءً والنفاية : الردي ينفي الريح : ما تنفيه الـــريح

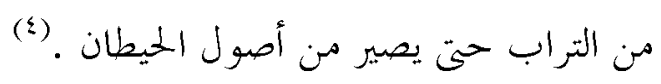

النفي اصطلاحاً :

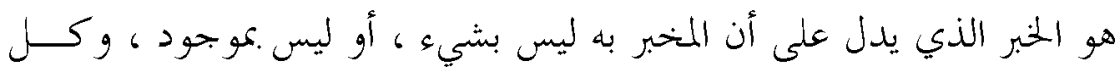

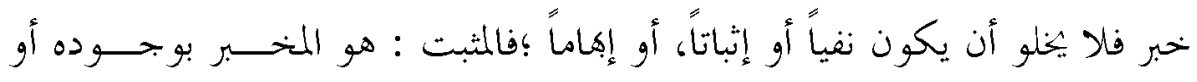

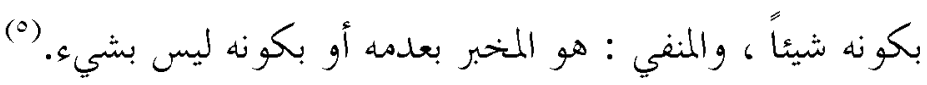

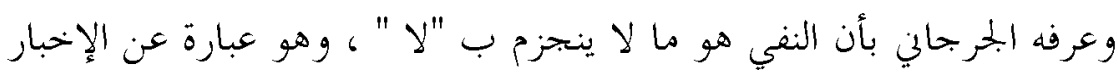

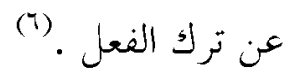

وعرفه زكريا الأنصاري فقال : النفي " قول دال على نفي الشيء " . (v)

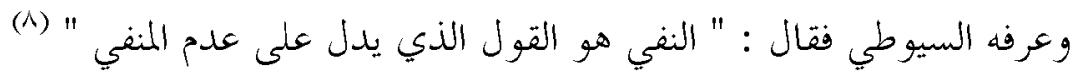

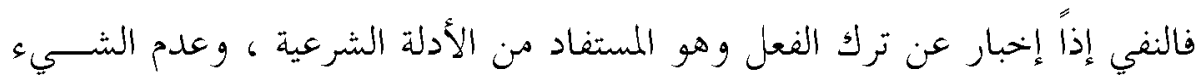

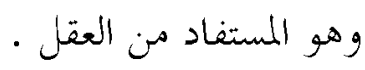




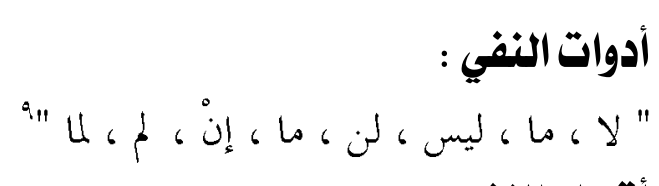

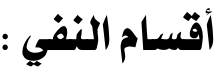

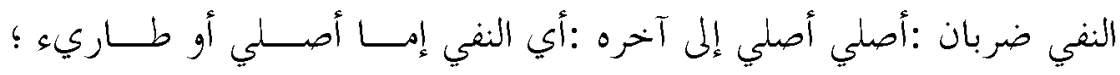

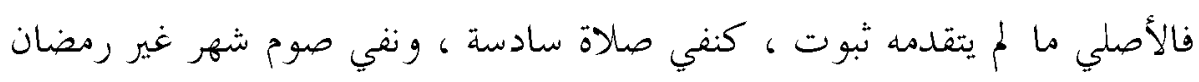

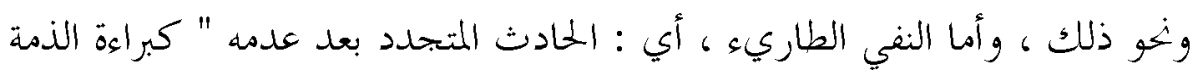

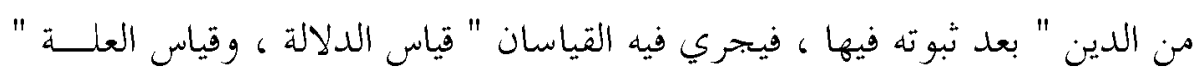

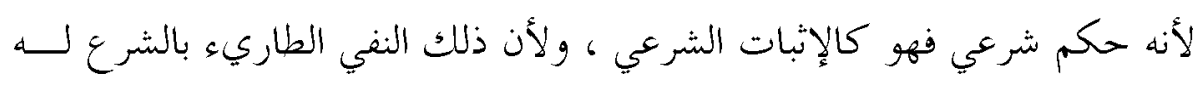

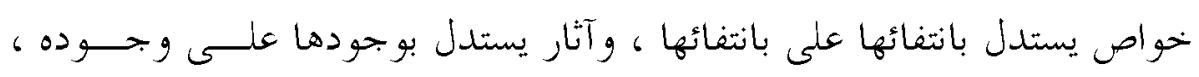

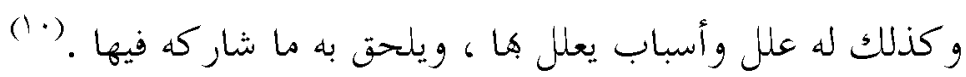

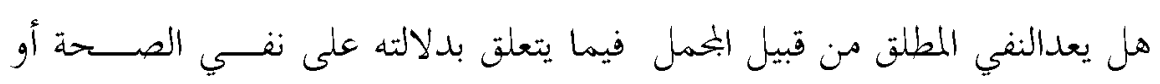
: Jl

إن حرف النفي قد يدخل على الماهية ويراد به نفــي الأصـل كقولــــ " لا

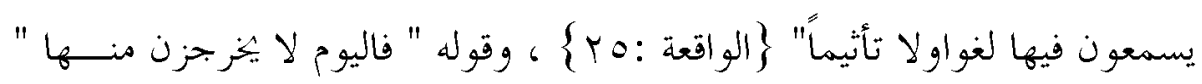
\} الجاثية :هب\{ وقد يراد به نفي الكمال مع بقاء الأصل كقوله " إهم لا أبمان لهم

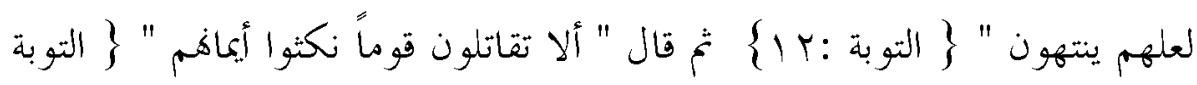
:

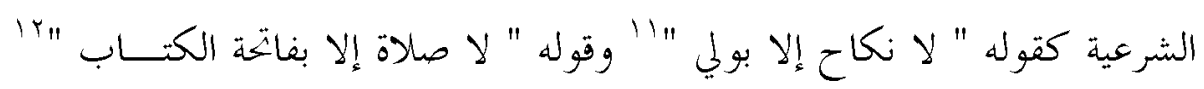

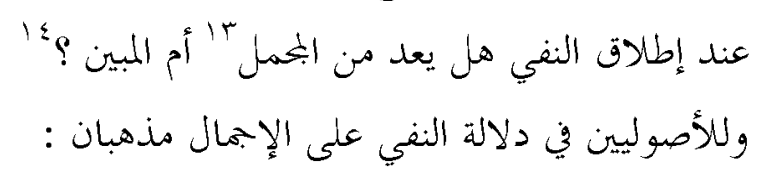

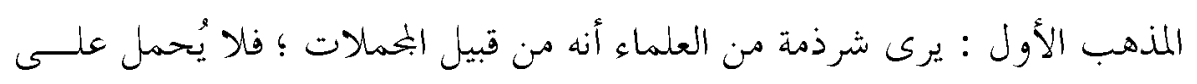
شيء إلا بدليل ولا تستقل بأنفسها في إثارة المعنى وهو منقول عن القاضــيين أبي 
بكر وعبد الجبار و الجمبائيين أبي علي وابنه ، وأبي عبد الله البصري ، و نقله الأســاذ

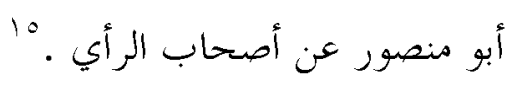

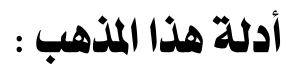

() ولأنه ظاهر في نفي الوجود وظاهر في نفي الحكم، وهو لا بمكن ؛ لأنـــ

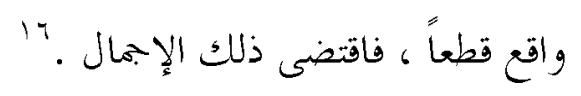

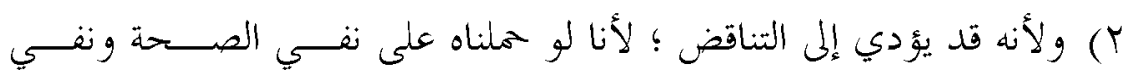

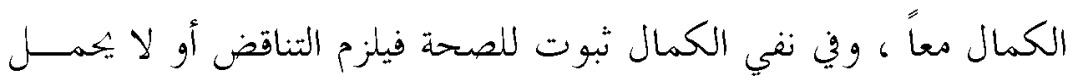

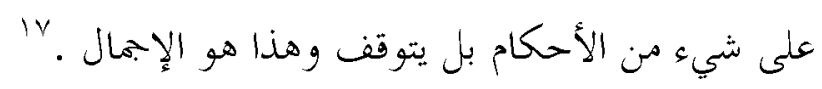

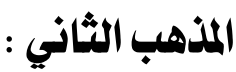

وهو قول جمهور العلماء من أهل الأصول منهم القفال الشاشي ، وأبو إسحاق، وأورده إمام الحرمين في التلخيص وذكرأن حمل النفي على البحمل من سجية الجهال

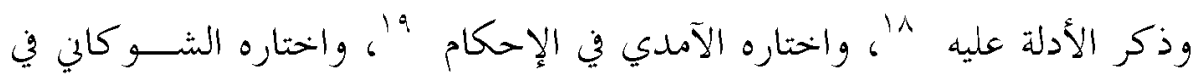

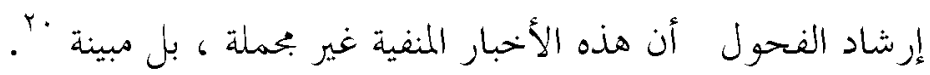

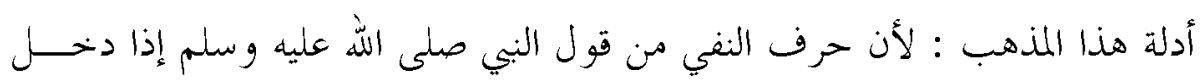

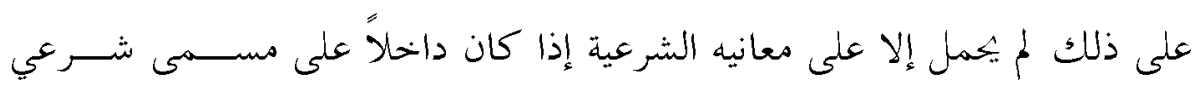

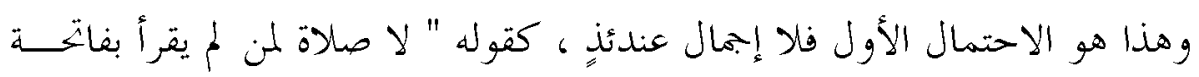

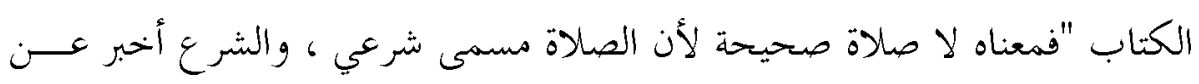
انتفاء ذلك ؛ فيجب تنزيل كلام الشارع على عرفه ، فيكون لفظه منزلاً على نفي الخي

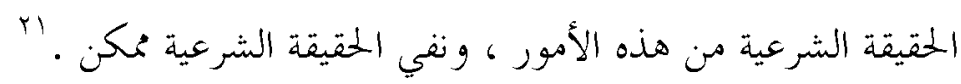

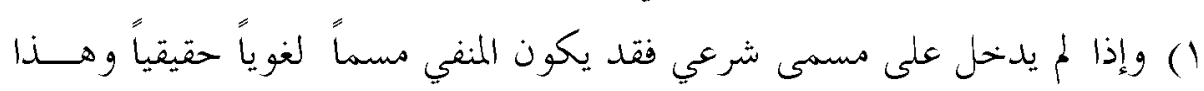

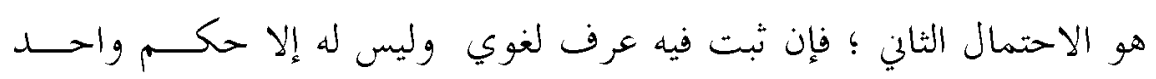

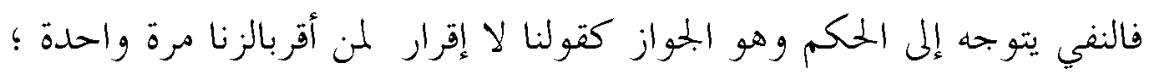

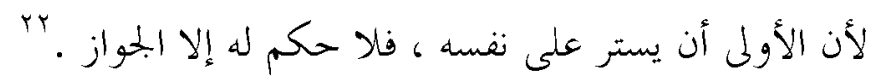




\section{أثر دلالة النفي في الخلاف الفقهي تطبيقاً على قراءة الفاتحة في الصلاة}

ب) أما الاحتمال الثالث فهو أن يكون له حكمان الفضيلة والجواز فلم يكن تعـيين

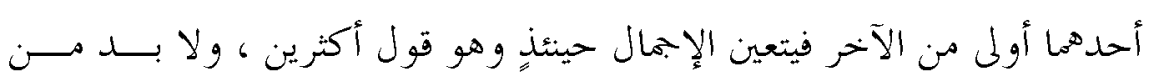

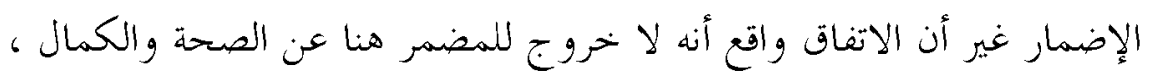

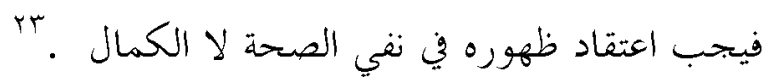

اختلاف العلماء في دلالة النفي على نفي الوجود أو الصحة والكمال :

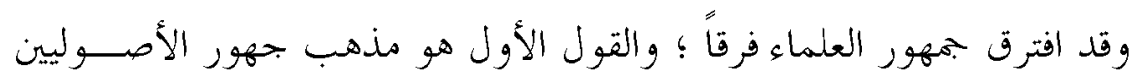
منهم الإمام الجحصاص وأبو بكر الباقلاي ذهبوا إلى أن النفي قد يراد به نفي الأصل

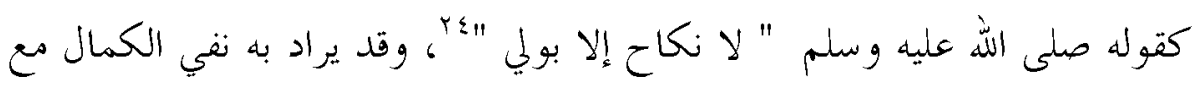

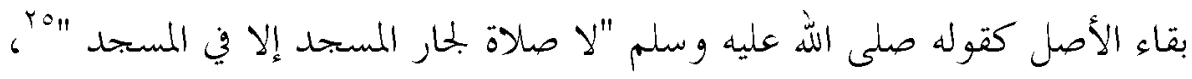

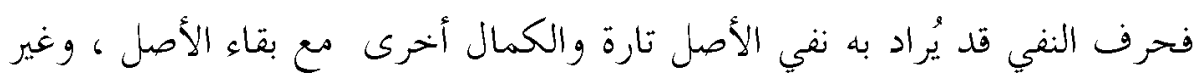

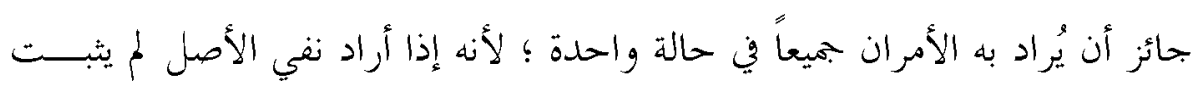
فيه شيء وإذا أراد إيباب النقص ونفي الكمال فقد دل بله بلا شك على أنى أن شيئاً منه

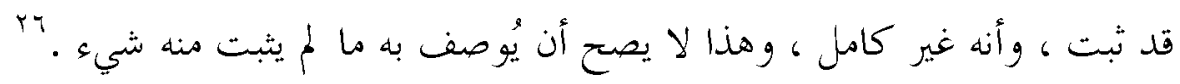

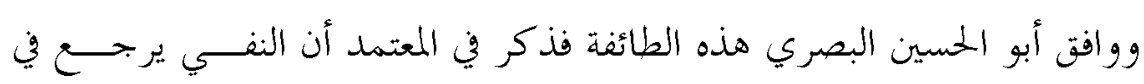

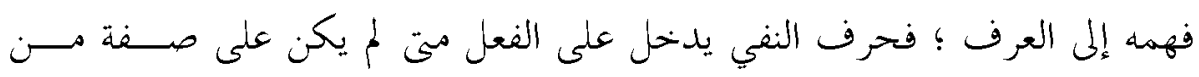

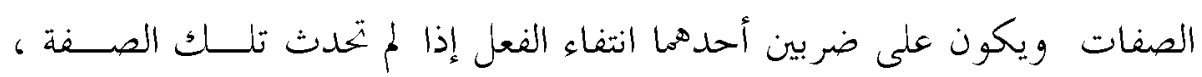

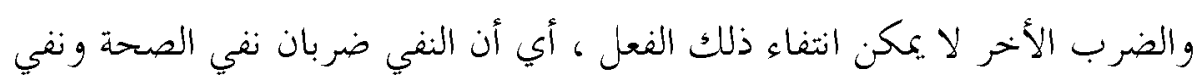
ir. J J

واستدل هذا الفريق بأدلة من القر آن والسنة : من القرآن : ورود عدة شواهد على نفي الأصل منها قوله تعالى " لا يسمعون

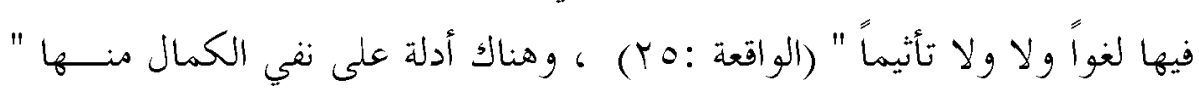

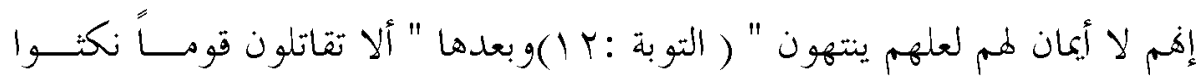

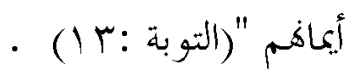


ومن السنة : وردت أدلة على نفي الأصل منها قوله صلى الله عليــهـ وســمم " لا

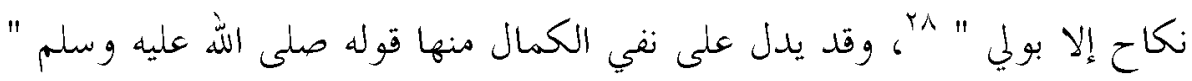

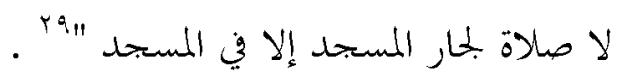

القول الثاني : رفض أصحاب هذا القول بجعل النفي من المخمالات ؛ فــالنفي عندهم من المستفلات من الكالام وبالتالي نفى هذا الفريق عن النفي صفة الإهـــام

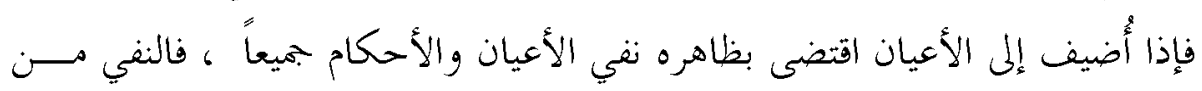
وجهة نظرهم لا يأتي لنفي الكمال بل لنفي الصحة وهذا ما ذهب إليه إمام الحرمين

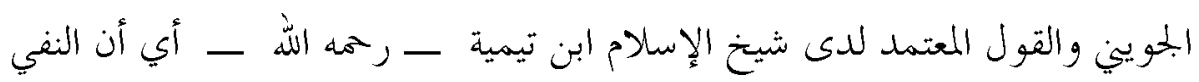

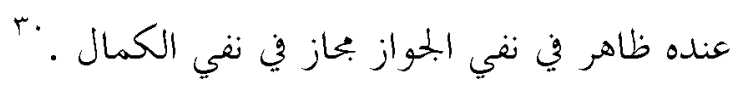
أدلة القول الثاني :

1) لأن النفي يتضمن نفي الجواز والكمال ؛ فإن نفي الكمال ينبيء عن ثبوت

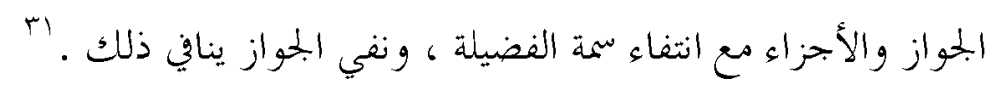
r) أنه لو صح حمل النفي الشرعي على نفي الكمال ، كما في قوله صلى الله عليه وسلم " لا صلاة لحار المسجد إلا في المسجد " لصح نفي صلاة عامة

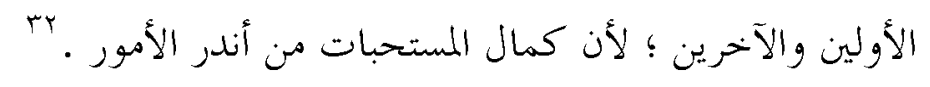

r) ولأن المنفي هو الذات الشرعية ، والتي وُجدت ليست ذات شرعية فيبى حمل الكالام على حقيقته ، وهي نفي الذات الشرعية ، فإذا وُجدد دليـل على أنه لا يتوجه النفي إليها كان توجهه إلى الصحة أولى ، لأهما أقرب

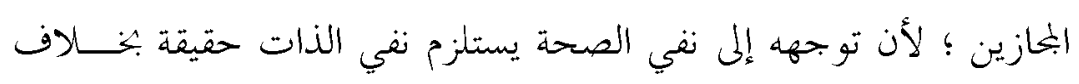
توجهه إلى الكمال ، فلا يستلزم نفي الذات ، فكان توجهه إلى الصــحة

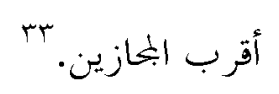




\section{أثر دلالة النفي في الخلاف الفقهي تطبيقاً على قراءة الفاتحة في الصلاة}

ويُفهم محا سبق أن الإمام الجويني والإمام ابن تيمية اعتــبرا أن النفـي في

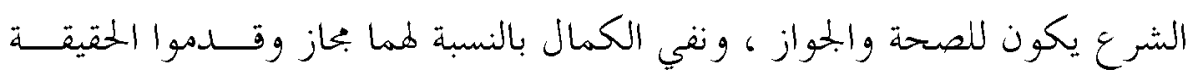
على البحاز فلم يعتدوا بنفي الكمال ، و بالبحث في المسألة وجددت أن نفي الــــات

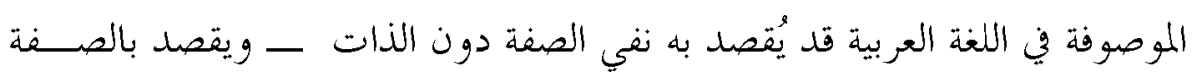

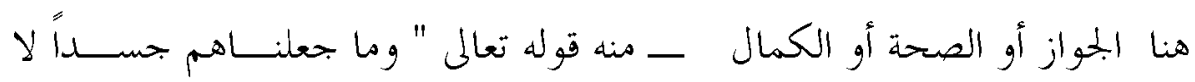
يأكلون الطعام " (الأنبياء:V) فالنفي هنا مُسلط على عدم أكلهم الطعام لا علــى كوهم جسداً ، فهم جسد يأكلون الطعام. وقد يُقصد بالنفي نفي الذات والصفة معاً منه قولـــهـ تعـالى "تعــرفهم

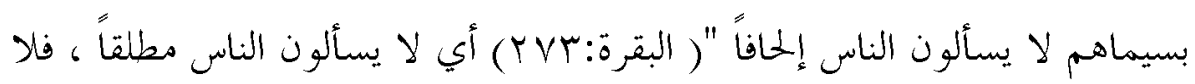
يكصل منهم إلحاف في المسألة ، ومنه أيضاً قوله تعالى " فما لهم من شــافعين ولا لاء صديق حميم " أي لا يكون لهم أي شفيع أبداً وبذلك انتفى الشفيع ووصفه . والنفي في النغة العربية أيضاً قد يُقصد به نفي الشيء كله لعدم كمــــال وصفه ، أو لانتفاء ثرته ، فمن أكل طعاماً لم ينتفع به يقول : ما أكلت شــيئاً ، وهذا الأسلوب موجود في القرآن الكريم منها قوله تعالى " ويتجنبها الأشقى الذي

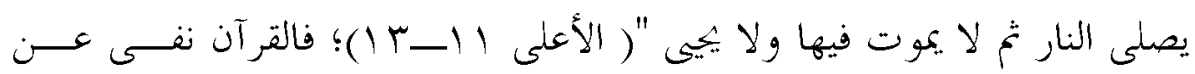

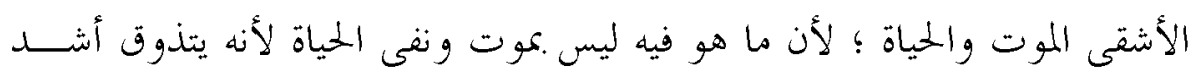
أنواع العذاب فلا ييى حياة طيبة . گ

ولذا فإن الباحثة ترجح القول الأول أي مذهب الجمهور ، وهو أن النفي

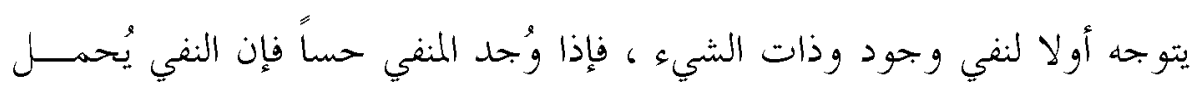
على نفي الصحة والمواز ، فإذا وُجدت على أدلة من الشرع على صحة المنفــي 
فإنـا نحمل النفي على نفي الكمال مثل قوله صلى الله عليه وسلم " لا صلاة لجـــــار المسجد إلا في المسجد "اهr ، لوجود أدلة أخرى من الشرع على صحة صلاته

\section{هل يصح تعليل الحكم الشرعي بالنفي ؟}

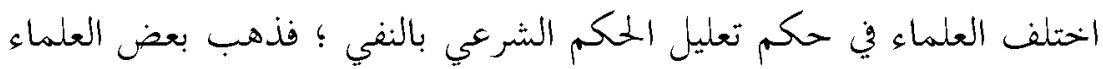

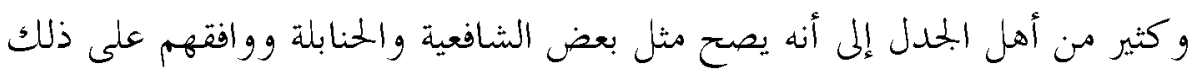

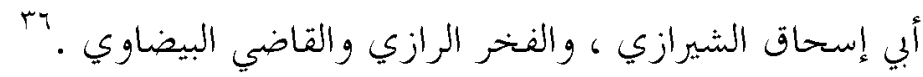

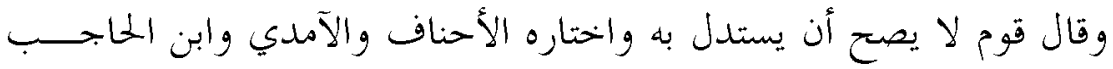
وتبعهما ابن السبكي، وقال الآمدي : منعه الأكثر.

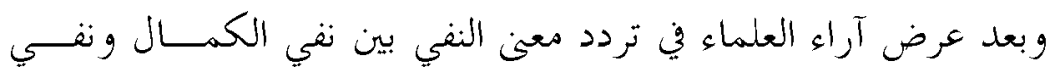

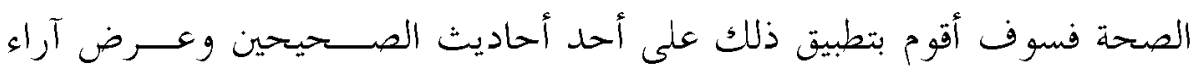
الفقهاء في المسألة . حدثنا علي بن عبد الله ، قال : حدثنا سفيان ، قال : حدثنا الزهري ، عن محمود

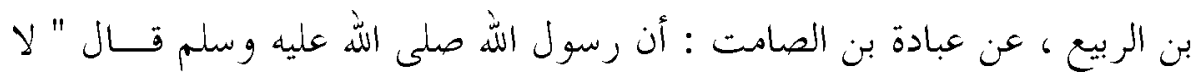

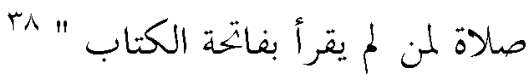

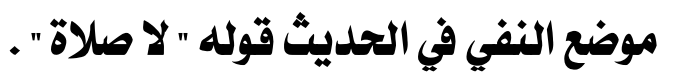

\section{شرح الحديث :}

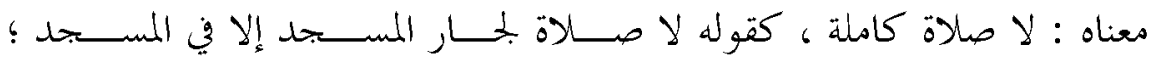

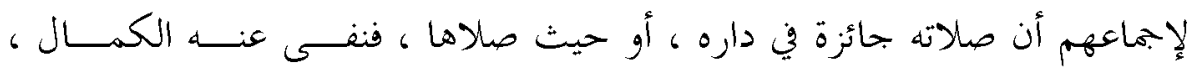
فكذلك هاهنا ، قالوا : وحديث عبادة ليس على العموم ؛ ويكملها الإمام عنه فيما أسر فيه إذا نسيها المأمو ، وحجة من أوجبها قوله :" لا صلاة لمن لم يقرأ بغاتحــة

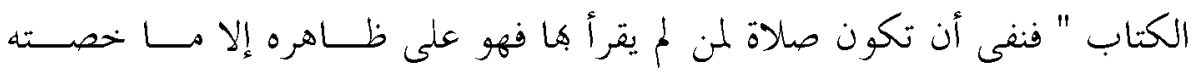

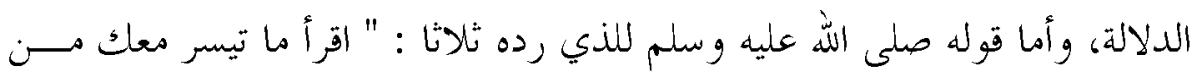




\section{أثر دلالة النفي في الخلاف الفقهي تطبيقاً على قراءة الفاتحة في الصلاة}

القرآن " ، فهو بحمل ، فكأنه قال : اقرأ ما تيسر معك من القـــرآن ، أي : اقـــرأ

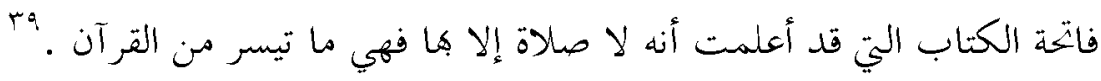

\section{أقوال العلمائ في حكم قرائة الفاتحة في الاصلاة :}

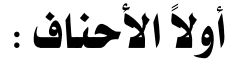

ذهب الأحناف إلى أن قراءة الفاتحة لا تتعين ركناً في الصلاة فالصلاة عندهم

تجزيء بدون الفاتحة فالواجب هو مطلق القراءة وأقله ثلاث آيات قصار ، أو آيــة

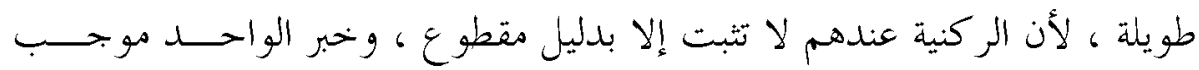

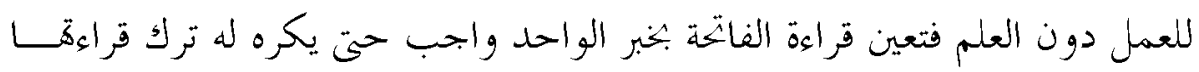

$$
\begin{aligned}
& \text { وتثبت الركنية بالنص . •؛ } \\
& \text { أدلة الأحناف : البركية بالن }
\end{aligned}
$$

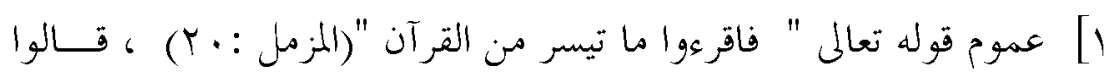

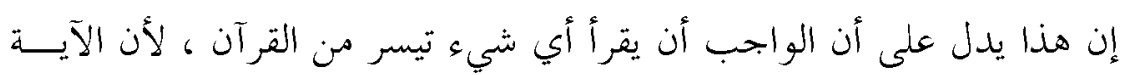

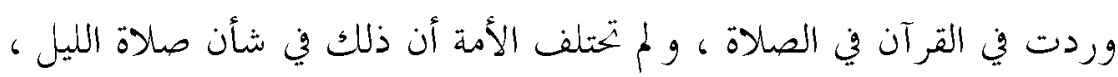

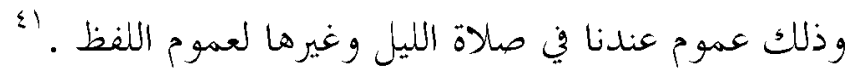

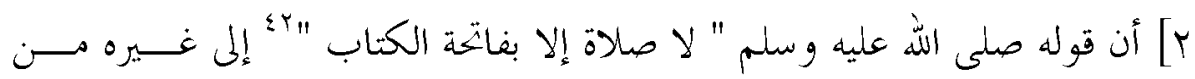

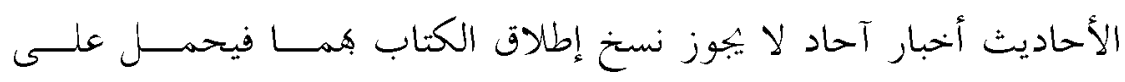
الوجوب دون الفريضة . r] واستدلو ابحديث أبي هريرة فقالوا : حديث أبي هريرة في تعليم الرجل صـلاته

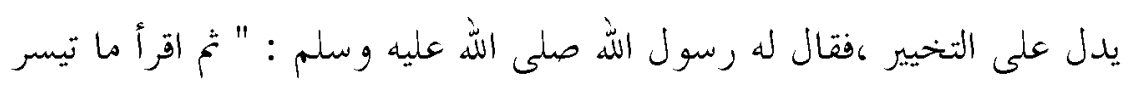

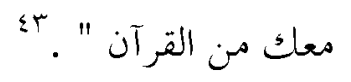
ع] أن قوله " لا صلاة " محمول على نفي الفضيلة كقوله " لا صلاة لمار المســــد إلا في المسجد " لا دلالة فيه على عدم الجواز بل على النقص . 


\section{رأي الجمهور :}

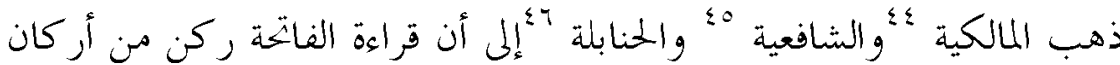
الصلاة ، فنجب قراءما في كل ركعة من كل صلاة ، فرضاً أو نفـلاًً ، جهريسةً كانت أو سريةً .

\section{واستدلوا بالأدلة التالية :}

] ما روى عن أبي هريرة أن رسول الله صلى الله عليه وسلم قال " من صسـلى

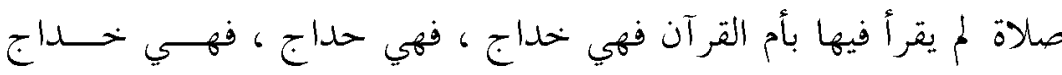
\&V "ثان

r ] " لا صلاة لمن يقرأ بفاتحة الفاتحة " استدل جمهور الفقهاء بظاهر الحـــديث على وجوب قراءة الفاتحة في الصلاة . r] و واستدل الجمهور بكديث أبي هريرة عندما قال البيي صلى الله عليه وســلم للمسيء صلاته :" وافعل ذلك في صلاتك كلها " بعد أن أمره بـــالقراءة،

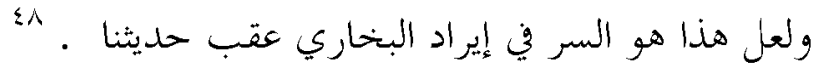

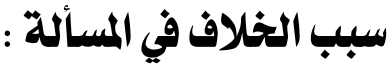

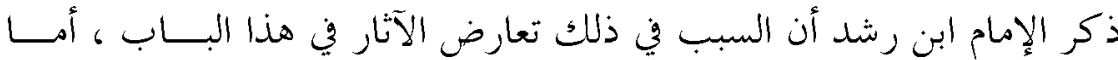
الآثار المتعارضة في ذلك فقد اختلف العلماء في تأويل الأحاديث الواردة في ذلــك رلك إلى مذهبين المذهب الأول : ذهبوا في تأويل هذه الأحاديث مذهب الجمع وإما أن يكونوا ذهبوا مذهب الرجيح ، من ذهب مذهب الجمع من أوجب قراءة ما تيسر

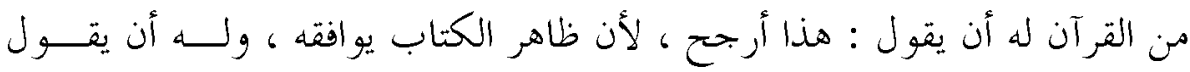

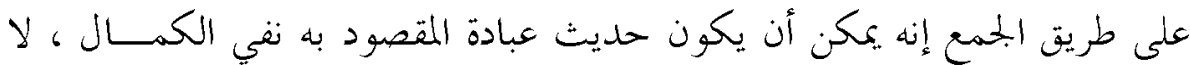
نفي الإجزاء ، وحديث أي هريرة المقصود منه الإعلام بالبمزيء مـن القـــرآن ، إذا

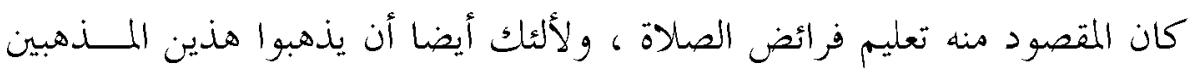

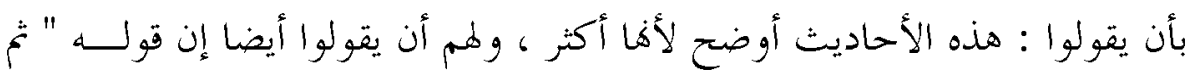




\section{أثر دلالة النفي في الخلاف الفقهي تطبيقاً على قراءة الفاتحة في الصلاة}

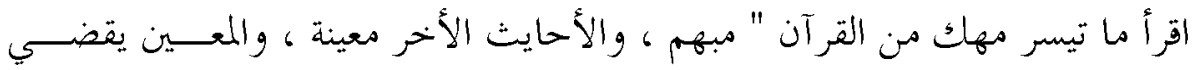

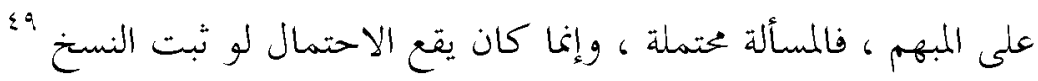

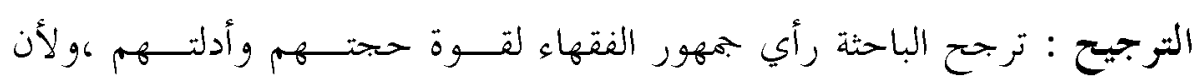

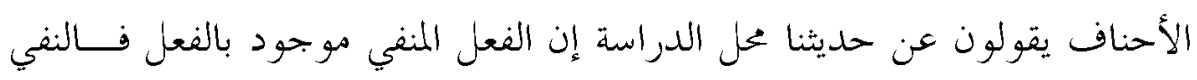
يرجع إلى حكم من أحكامه، وليس حكم بأولى من حكم آخر لأن الفعل المنفــي

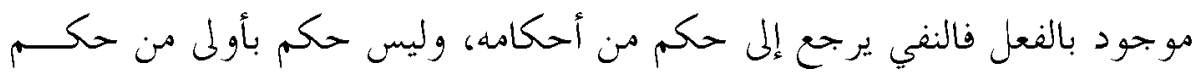

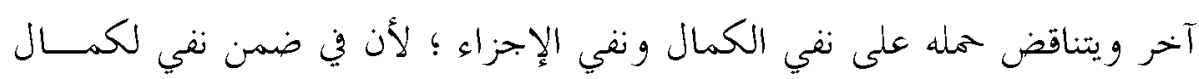

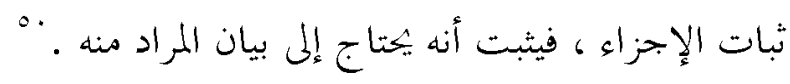

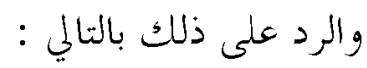

1) هذا الخحبر ليس بمجمل ، بل يدل بظاهر على نفي تحقق صالاة شرعية ، لأن

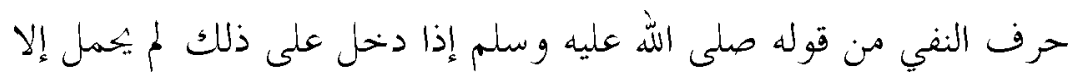

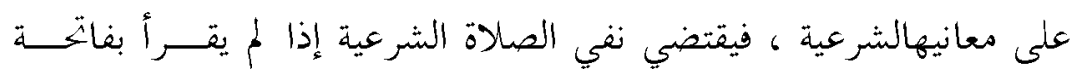

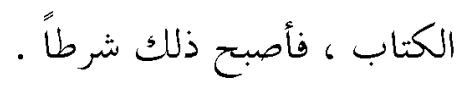

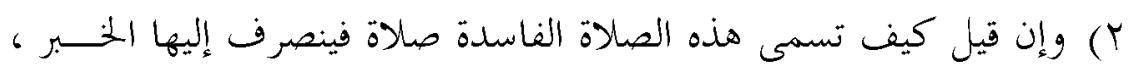

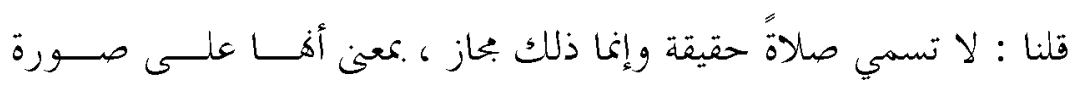

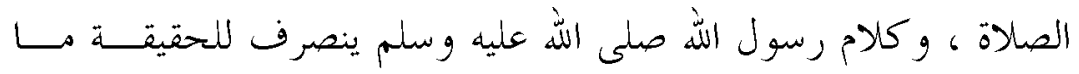

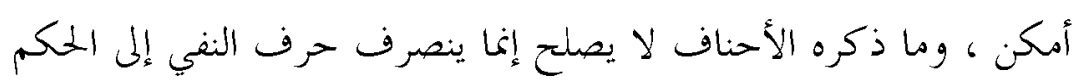

$$
\text { إذا لم بمكن صرفه إلى ما أضيف إليه . }
$$

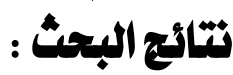

( ) لكل مصطلح فقهي أو أصولي علاقة ما بين معناه الاصطلاحي وأحد معانيه

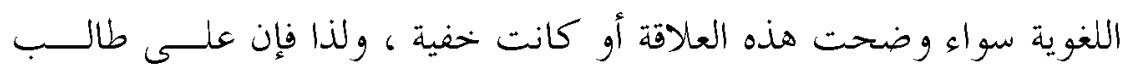
العلم الشرعي أن يجمع بين العلوم الشرعية وعلوم اللغة العربية . r) تنوع أقسام النفي تننوع فهناك نفي أصلي و نفي طاريء . 
ץ) الأصل في اللغة العربية أن يكون مطلق النفي لنفي حقيقة وماهية الشـيء ، وأن صرف النفي على نفي الكمال يكون بحازاً .

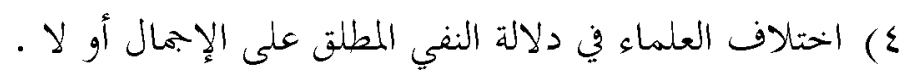
ه) اختلاف العلماء في إمكانية الاعتماد على النفي في تعليل الأحكام الشرعية . ج) للنفي أثر واضح في اختلاف الفقهاء ، ولكل فقيه وجهة نظره في الترجيح ،

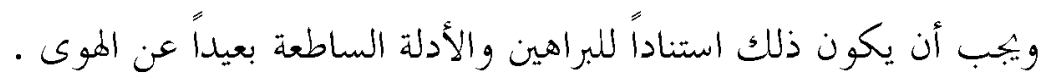

\section{الأصادر والمراجع : ( مرتب حسب تاريخ الوفاة ) \\ أولا القرآن وعلومه : 1) القرآن الكريم r) أحكام الاقرآن}

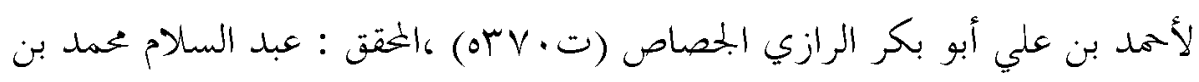

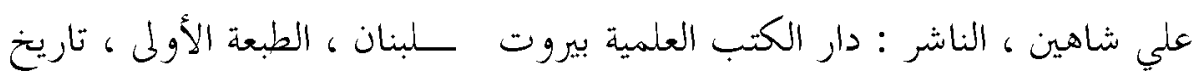

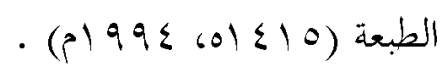
كتب الحديث وعلومه :

() (صحيح البخاري ،لخمد بن إسماعيل أبو عبد الله البخاري الجعفي ، الناشـــــ دار

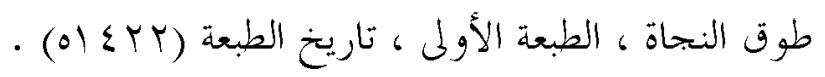

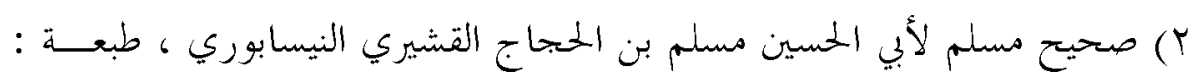

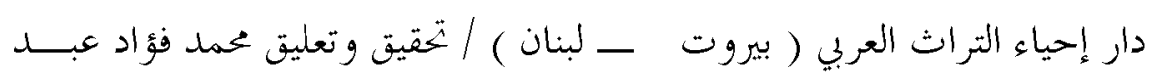
· الباقي

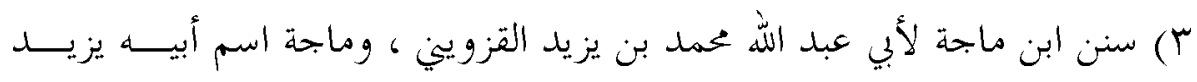

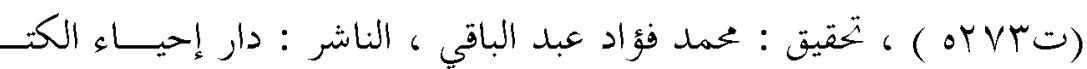

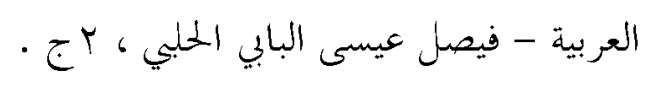




\section{أثر دلالة النفي في الخلاف الفقهي تطبيقاً على قراءة الفاتحة في الصلاة}

ع) سنن أبي داوود ، لألبي داوود سليمان الأشعث بن إسحاق بن بشير بن شـــداد

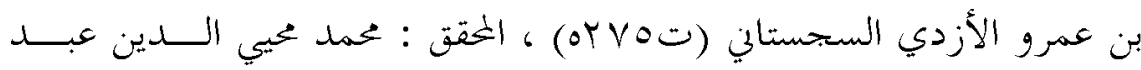

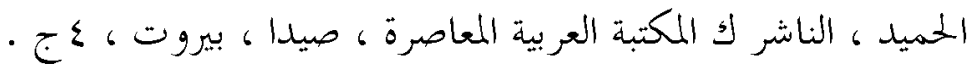

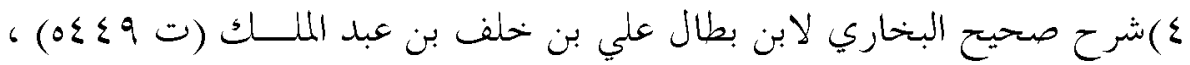

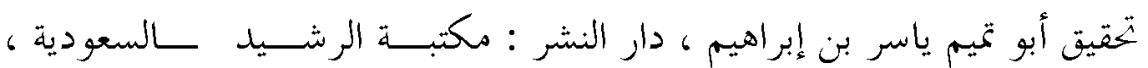

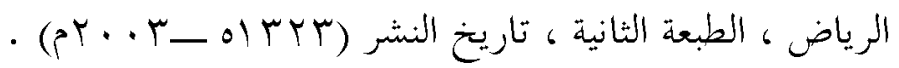

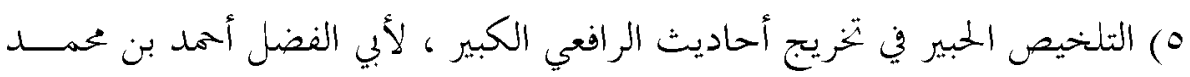

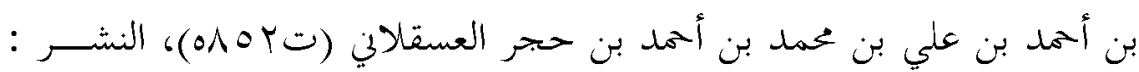

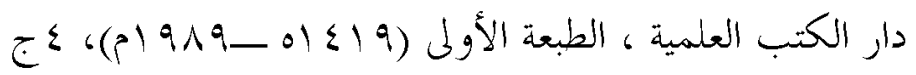

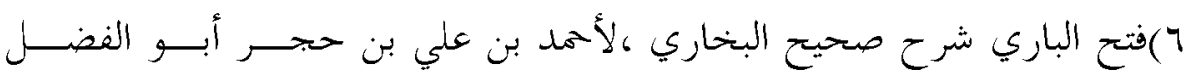

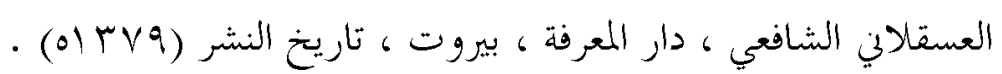

\section{كتب أصول الفقه :}

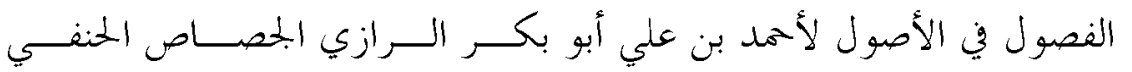

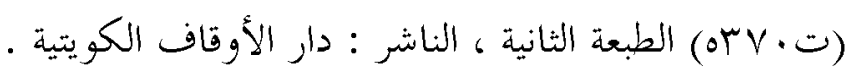

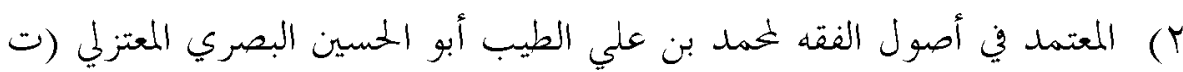

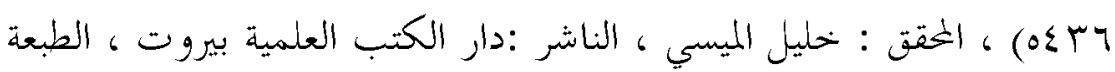

$$
\text { الأولى (1) }
$$

r) التبصرة في أصول الفقه لأبي إسحاق إبراهيم بن علي بن يوسف الشــيرازي

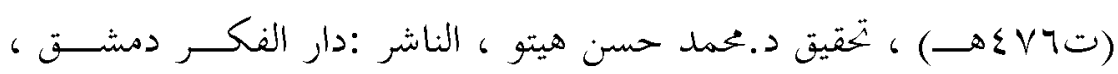

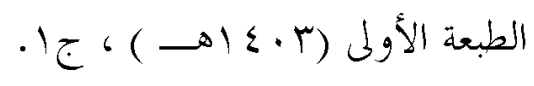

ع) التلخيص في أصول الفقه لعبد الملك بن عبد الله بن يوسف بن محمد الجــــيني

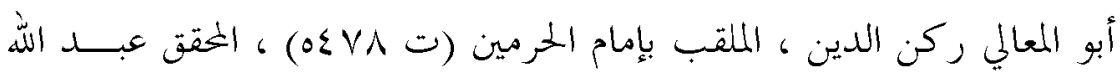
جو لم النبالي وبشير أحمد العمري ، الناشر : دار البشائر الإسلامية ، بيروت . 
0) المنخول لخمد بن محمد الغزالي الطوسي (ته .00) ، حققه د// محمد حسسـن

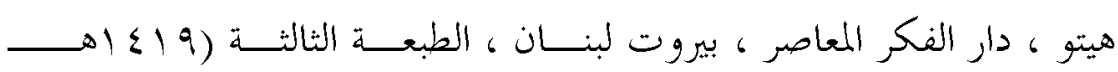
( $)$ ( 991 المستصفى لأبي حامد محمد بن محمد الغزالي الطوسي (ت 0. ه0 ) ، الناشر :

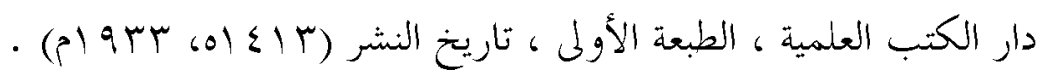

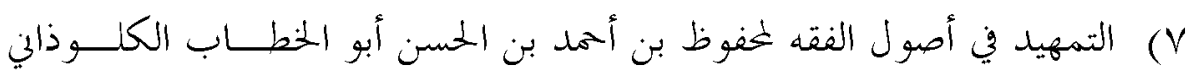

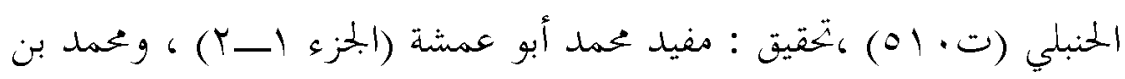
علي بن إبراهيم (الجزءء بـــ) ، الناشر : مركز البحث العلمي وإحياء التراث

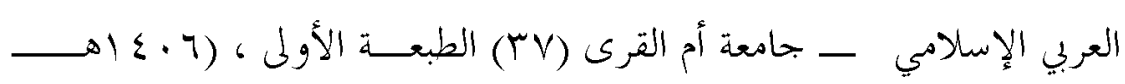

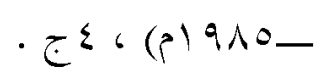

ه) الواضح في أصول الفقه لأبي الوفاء علي بن عقيل بن محمد بن عقيل البغدادي

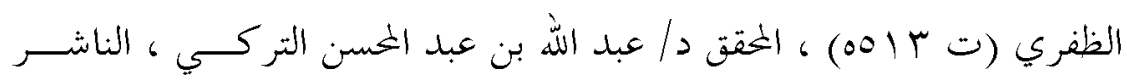

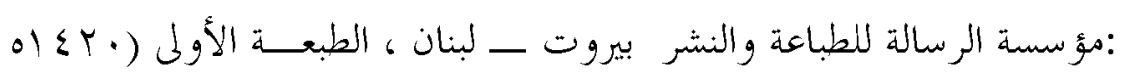
- (p) $999-$ 9) الخصول للرازي أبي عبد الله محمد بن عمر بن الحسن بن الحســين الـــرازي

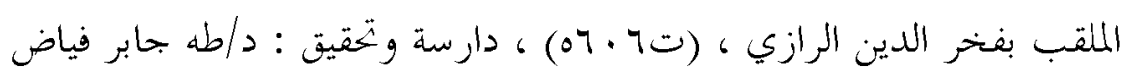

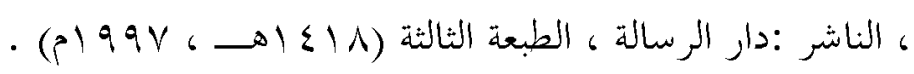
• () الإحكام أبي الحسين سيد الدين عليي بن أبي علي بن محمد بن سالم الــثعلبي الآمدي (ت اسبها)، الخحقق عبد الرازق عفيفي ، الناشر : المكتب الإسلامي لئي

$$
\text { بيروت ، دمشق لـلبنان . }
$$

(1) شرح مختصر الروضة لسليمان بن عبد القوي بن الكريم الطوفي الصرصري أبو

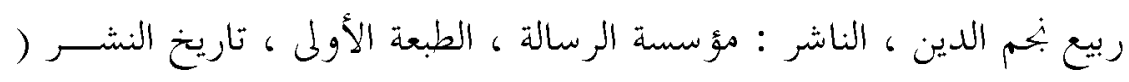

$$
\text { ( ) } 9 \lambda V-01 \varepsilon \cdot V
$$




\section{أثر دلالة النفي في الخلاف الفقهي تطبيقاً على قراءة الفاتحة في الصلاة}

r ( ) البحر الخيط في أصول الفقه ، لأبي عبد الله بدر الدين محمد بن عبد الله بــن

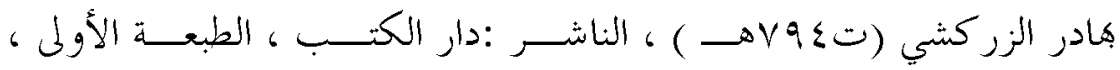

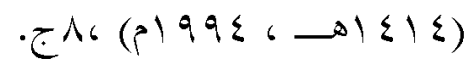

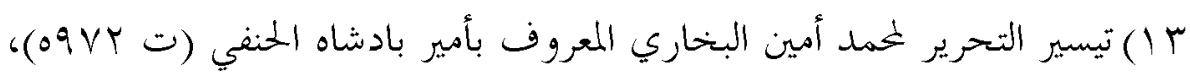

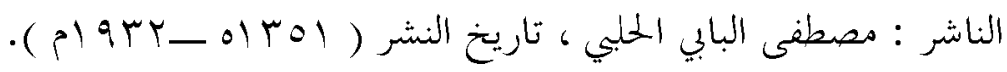

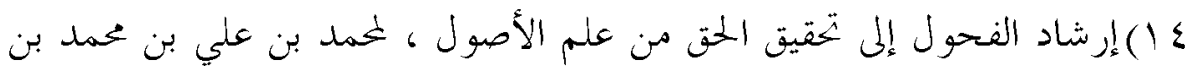

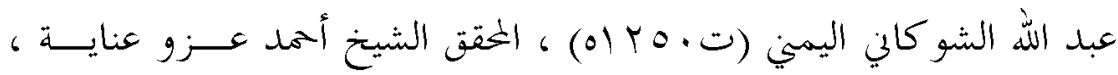

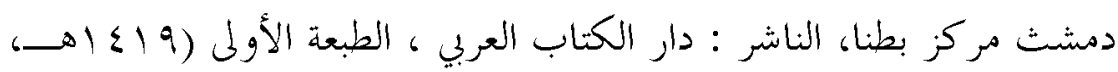

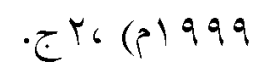

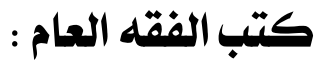

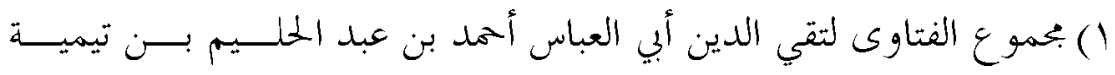

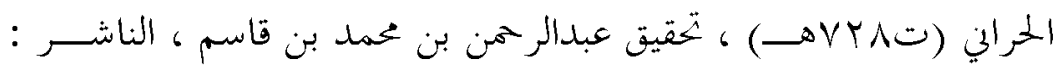
بمقع الملك فهد لطباعة المصخف الشريف ، المدينة المنورة ، السـعبودية

$$
\text { - ( } 19906 \longrightarrow 1 \leqslant 17)
$$

\section{كتب الفقه : أولة}

\section{أولاً : كتب الفقله الحنفي : الحتي}

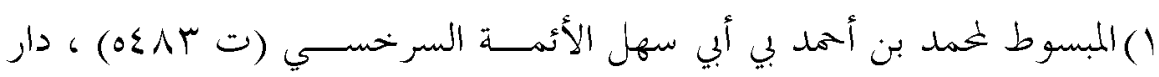

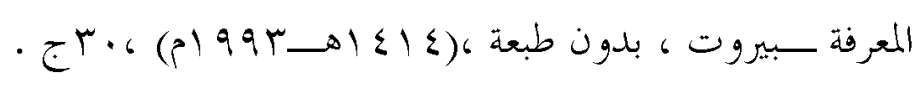

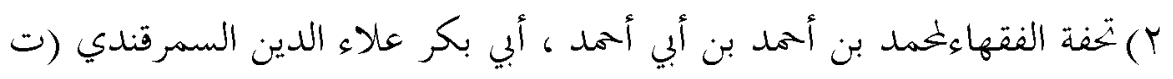

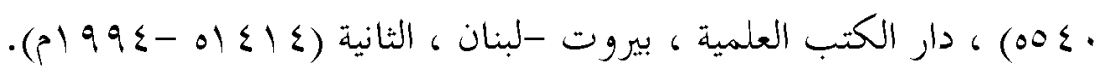

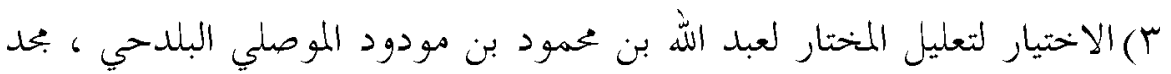

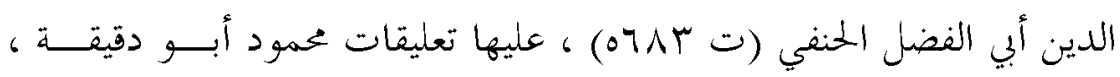

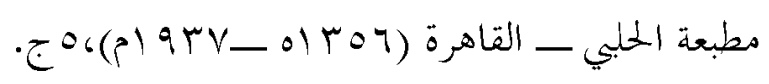


ع) تبيين الحقائق شرح كتز الدقائق وحاشية الشبي لعثمان بن علي بــن مجهـن

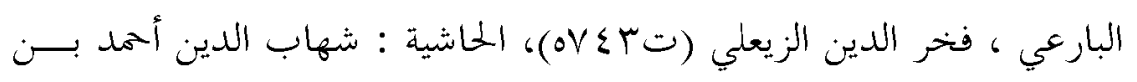

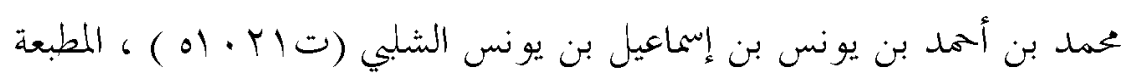

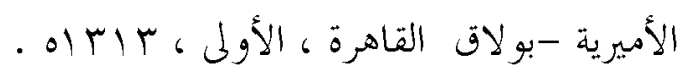

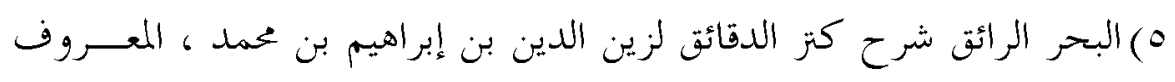

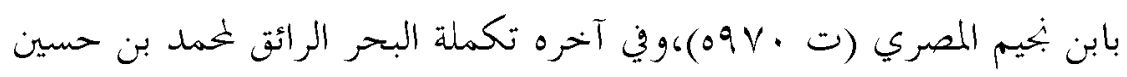

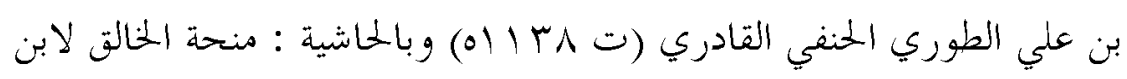

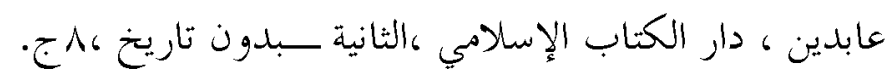

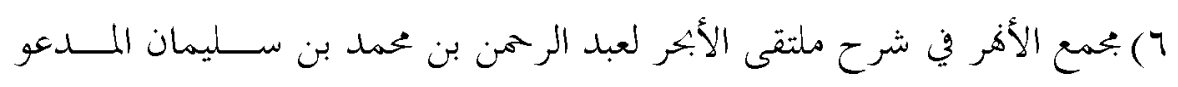

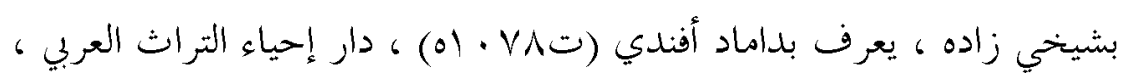

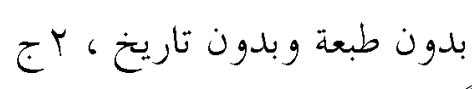

ثانياً : كتب المذهب المالكي ون ونان تاني

(الكافي في فقه أهل المدينة لأبي عمر يوسف بن عبد الله بن معمد بن عبد البر بن

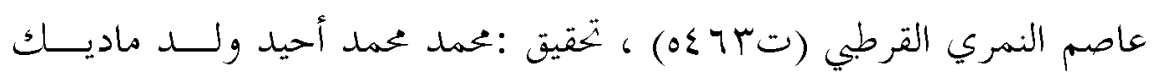

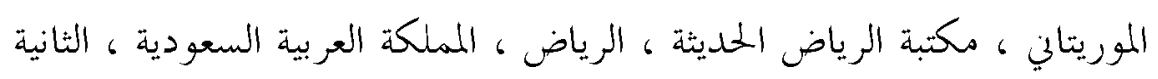

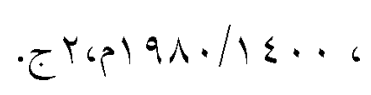

ץ)بداية المختهد وهاية المقتصد لألي الوليد محمد بن أحمد بن محمد بن أحمد بن رشد

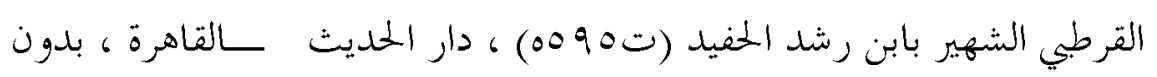

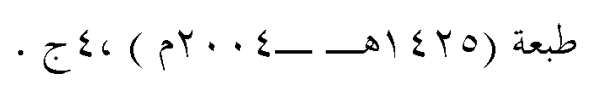

ب) الذخيرة لأبي العباس شهاب الدين أحمد بن إدريس بن عبد الــرحمن المـالكي

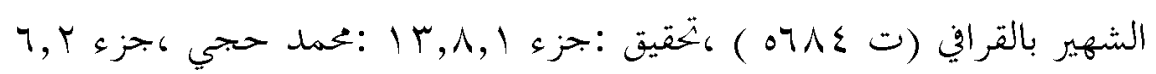

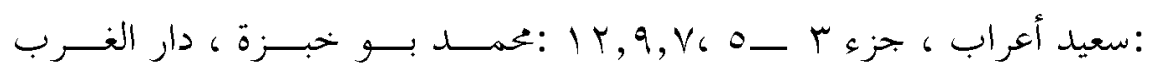

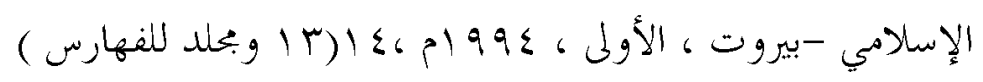




\section{أثر دلالة النفي في الخلاف الفقهي تطبيقاً على قراءة الفاتحة في الصلاة}

\section{ثالثا :كتب الملذهب الشافهي}

(الأم للشافعي أبي عبد الله محمد بن إدريس بن العباس بن عثمان بن شــافع بــن

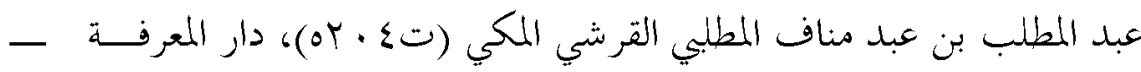

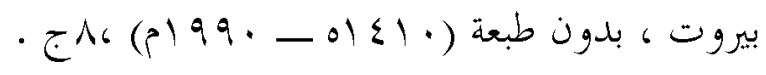

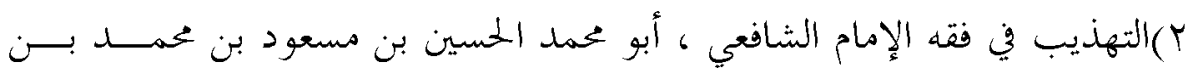

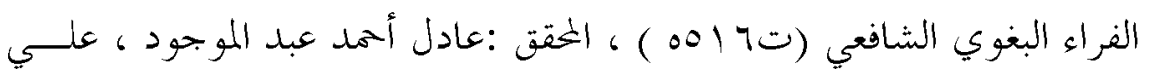

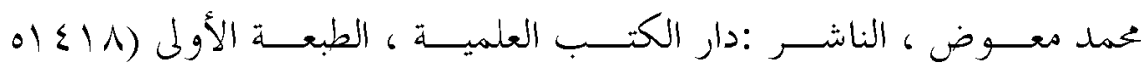
$\cdot e^{\lambda \in}(5) 99 \gamma_{-}$ ب)ابخموع شرح المهزب ، أبو زكريا محيي الدين يهـيى بــن شــرف النـووي

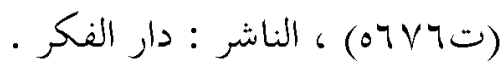
ع) أسنى المطالب في شرح روض الطالب ، لزكريا بن محمد بن زكريا الأنصاري ،

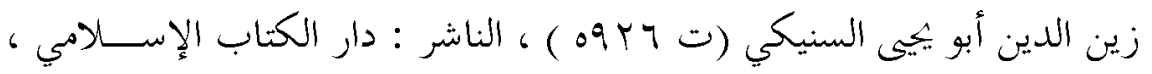

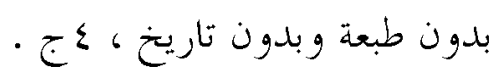

ه) هاية المختاج إلى شرح المنهاج ، شنس الدين محمد بن أبي العباس أحمد بن حمـــة

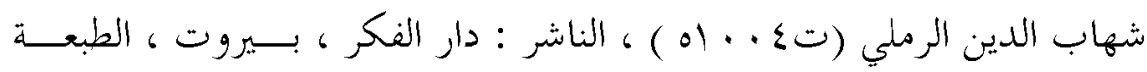

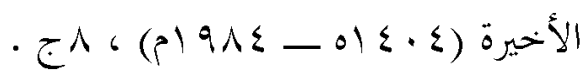

$$
\begin{aligned}
& \text { رابعاً : كتب المذهب الحنبلي }
\end{aligned}
$$

() الكافي في فقه الإمام أحمد لأبي محمد موفق الدين عبد الله بن أحمد بن محمد بــن

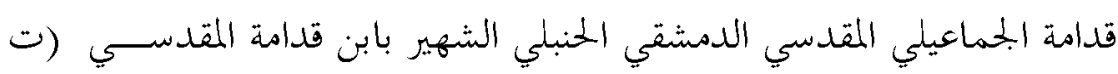

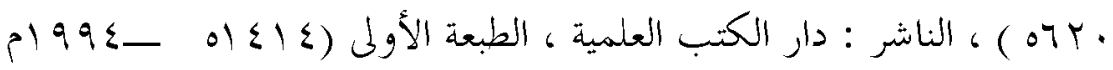

$$
\text { - } \leqslant 6(
$$


Y) المغني في فقه الإمام أحمد بن حنبي الشيباني لأبي محمد موفت الدين عبد الله بــن

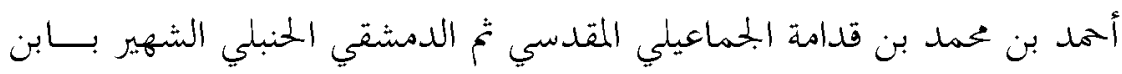

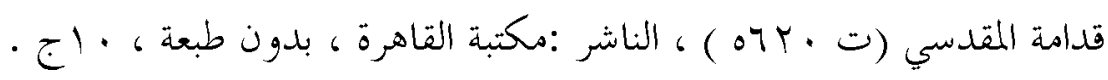
r) كشاف القناع عن متن الإقناع لمنصور بن يونس بن صلاح الدين بن حسن بن

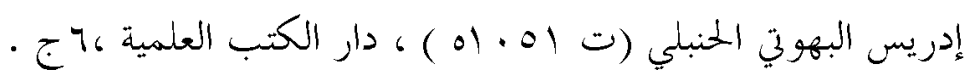

\section{الخريب المعاجم ولغة الفقهاي}

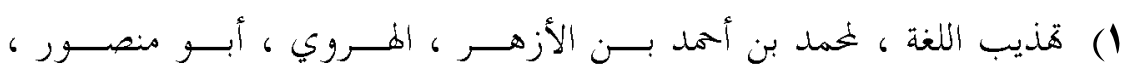

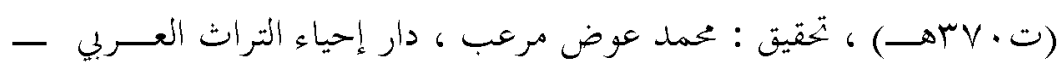

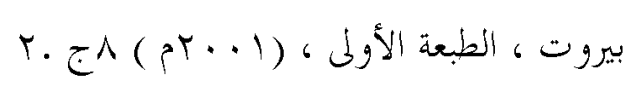

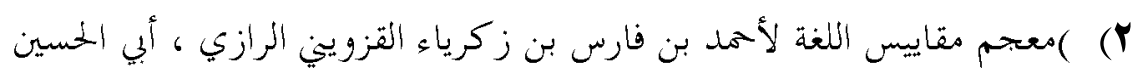

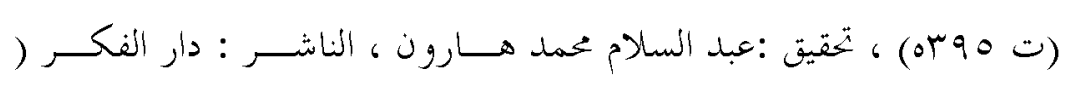

$$
\text { - } 7 \text { ( ) }
$$

r) لسان العرب ، لمحمد بن مكرم بن علي ، أبو الفضل ، جمال الدين اين منظور

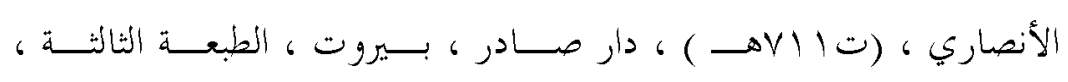

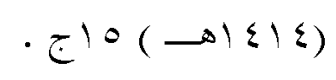

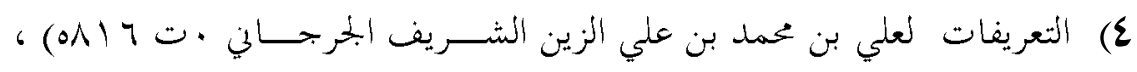

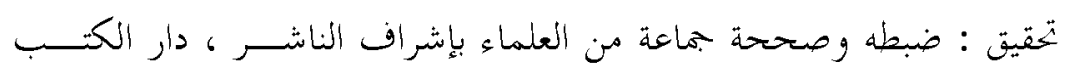

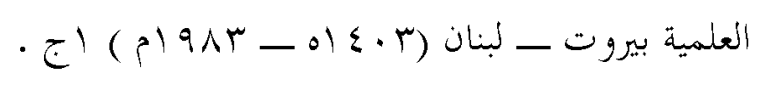

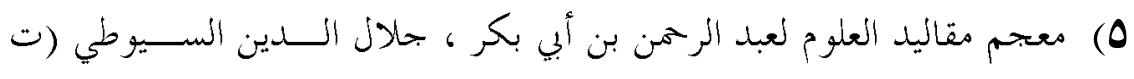

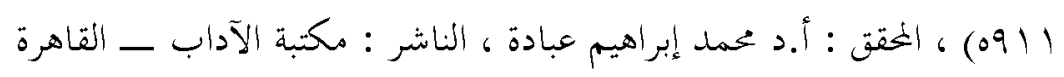

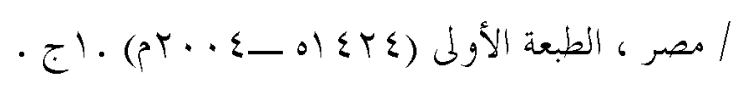

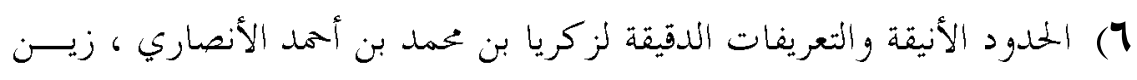

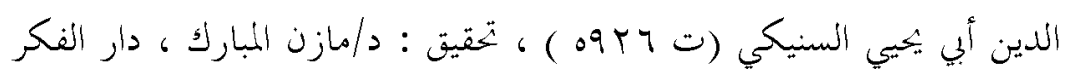

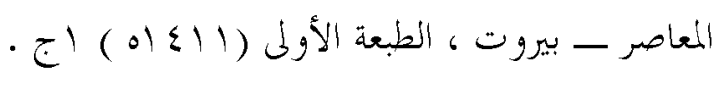




\section{أثر دلالة النفي في الخلاف الفقهي تطبيقاً على قراءة الفاتحة في الصلاة}

\section{كتب الأدب والبلاغة :}

1. البالاغة العربية لعبد الرحمن بن حسن حنبكة الميداني الدمشقي (ته بم اهــ )

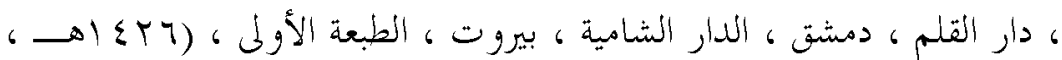

- (p) 997

r. كتب النحو :المفصل في صنعة الإعراب ، لأبي القاسم محمود بن عمرو بن أحمد

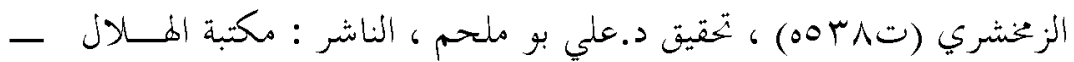

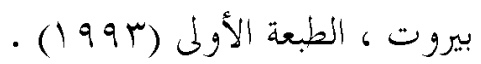

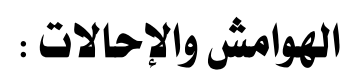

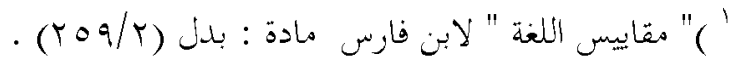

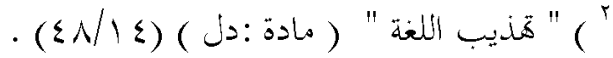

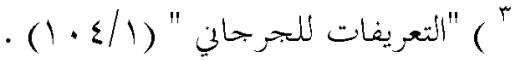

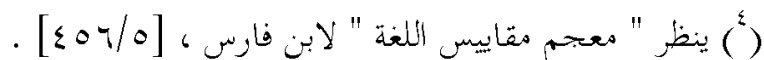

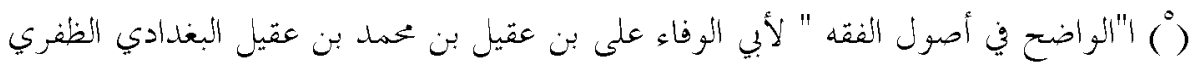

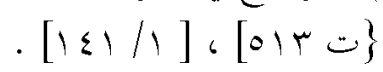

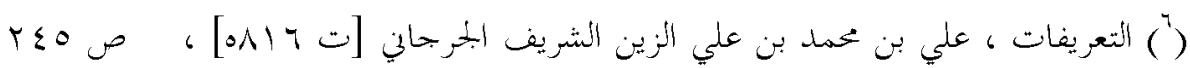

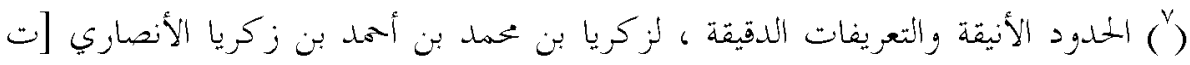

$$
\text { . A } \wedge \text { ص [094 }
$$

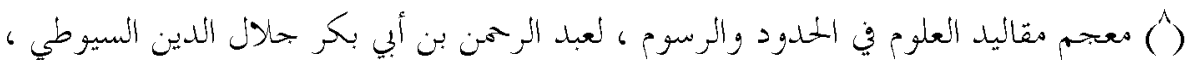

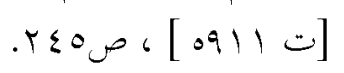

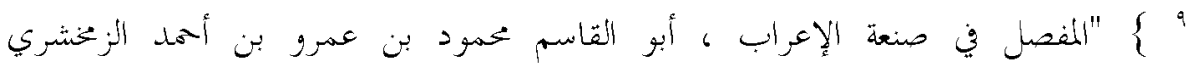

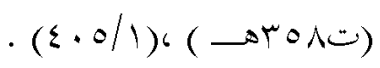

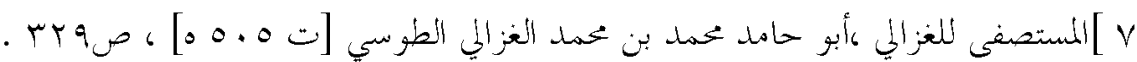

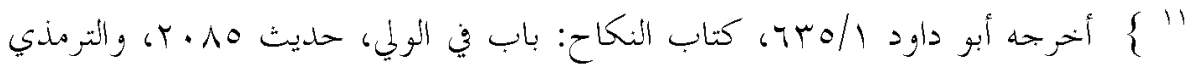

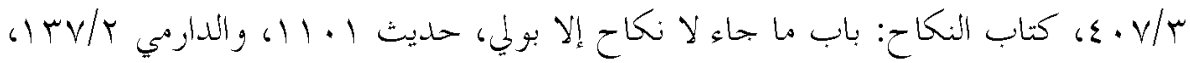

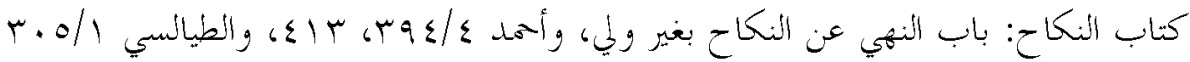

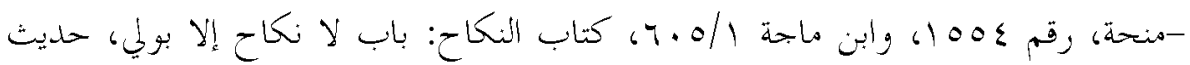

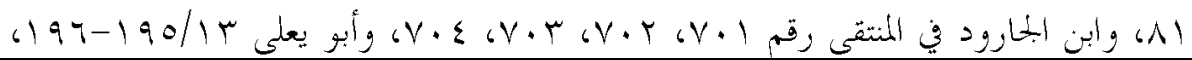


رقم

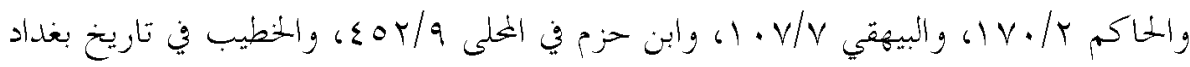

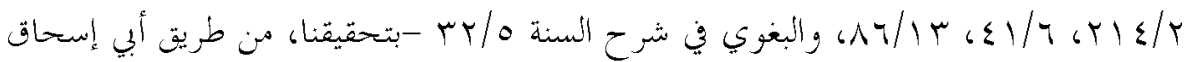

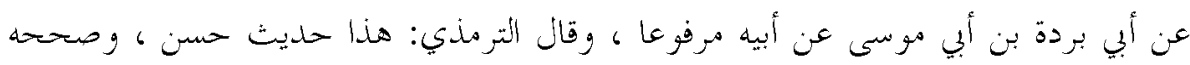
ابن حبان.

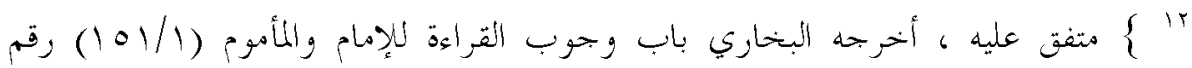

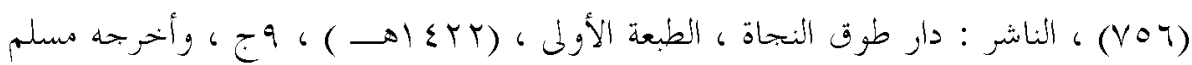

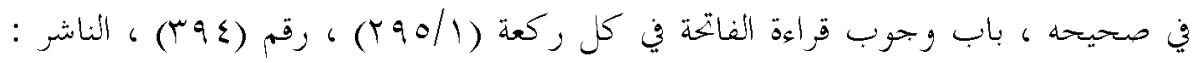

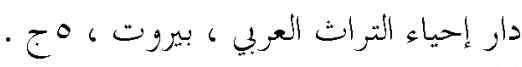

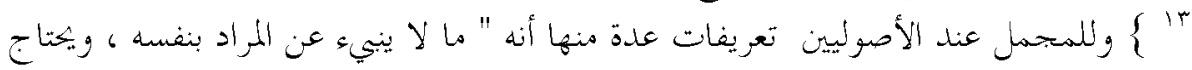

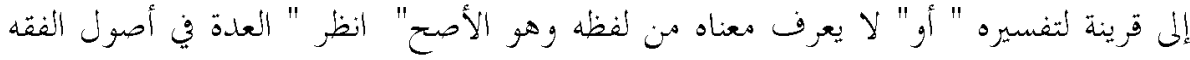

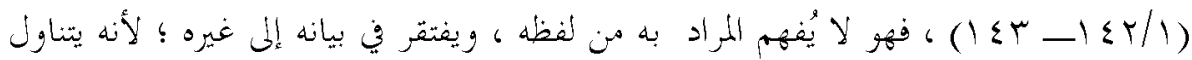

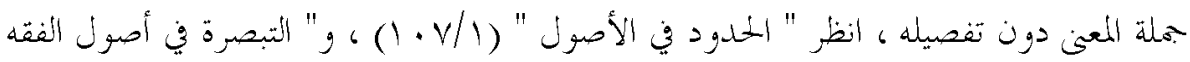

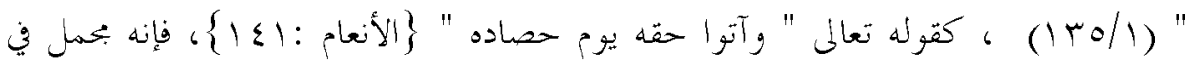

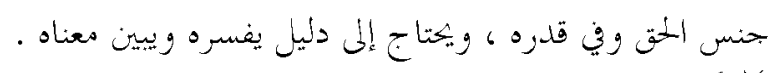

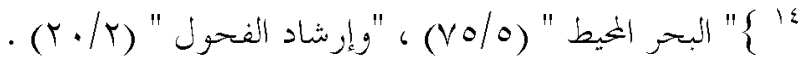

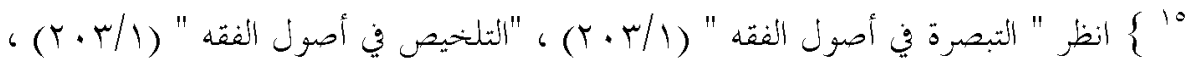

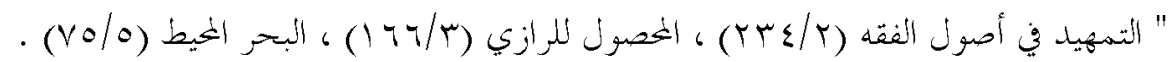
" 14

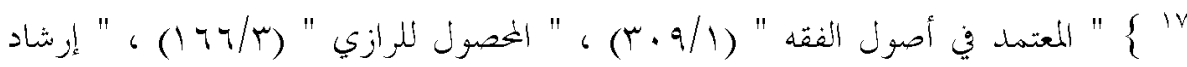

$$
\text { الفحول "(r/r/r) }
$$

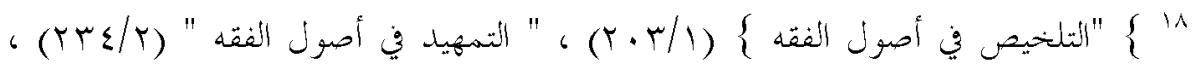

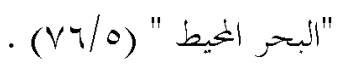

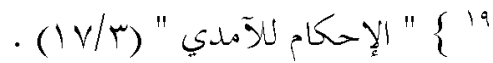

$$
\begin{aligned}
& \text { • }
\end{aligned}
$$

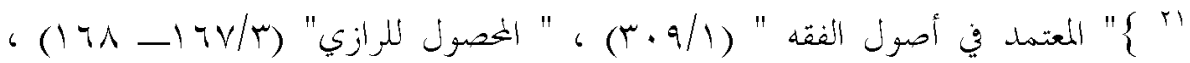

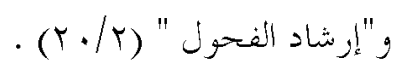

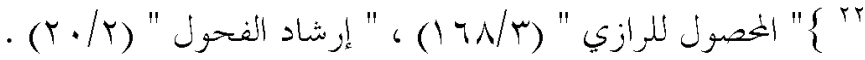
. 
.

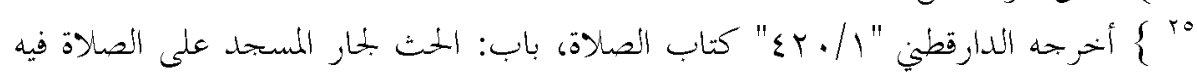

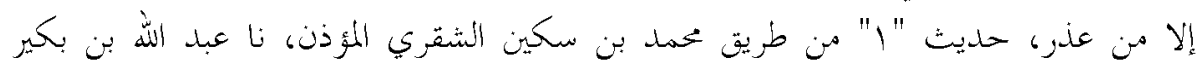

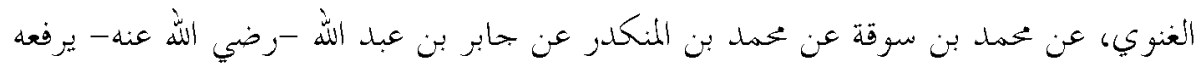

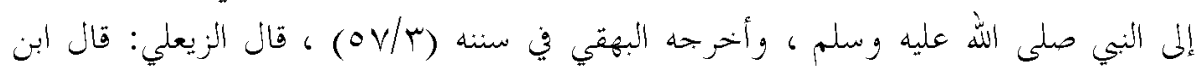

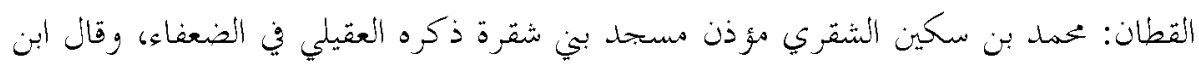

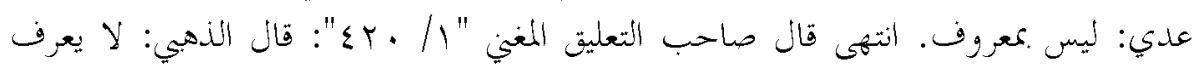

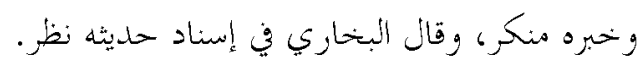

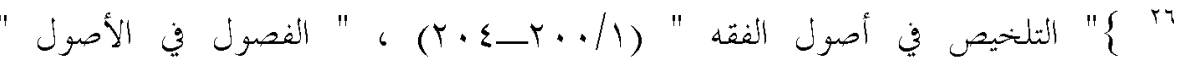

$$
\begin{aligned}
& \text { - (ror_rol/1) }
\end{aligned}
$$

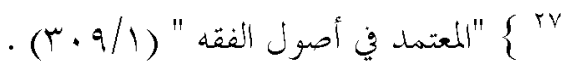

$$
\begin{aligned}
& \text { N } \\
& \text { أن }
\end{aligned}
$$

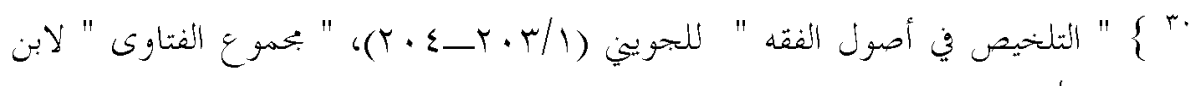

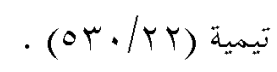

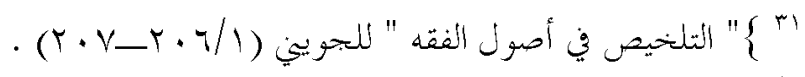

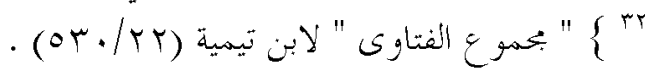

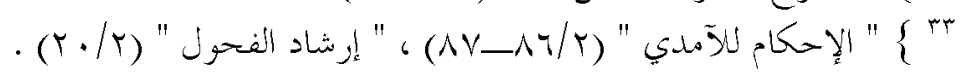

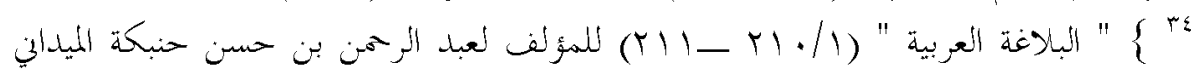

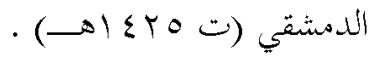

$$
\begin{aligned}
& \text { 年 }
\end{aligned}
$$

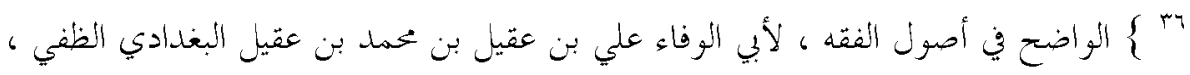
عال $\}$

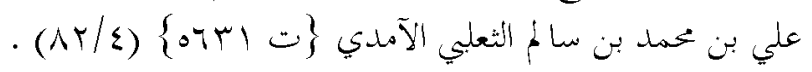

ك

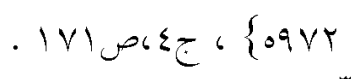

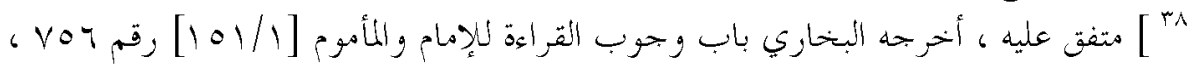

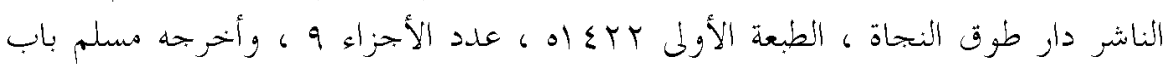




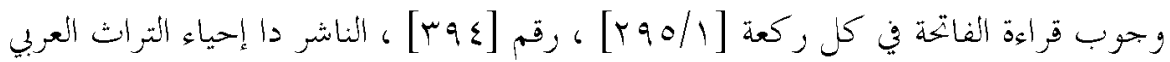

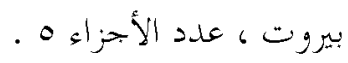

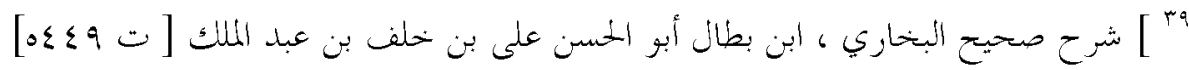
. $[r \div 9, r v \cdot / r] ،$

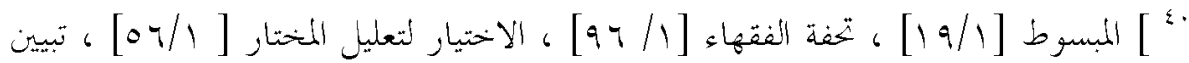

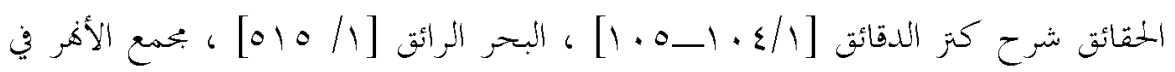

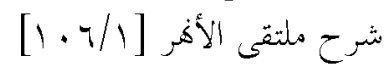

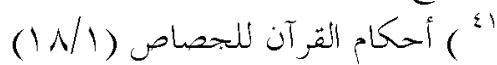
.

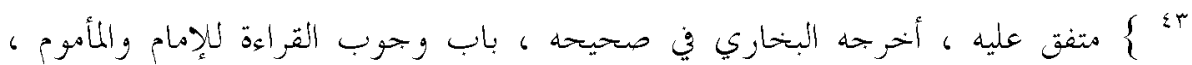

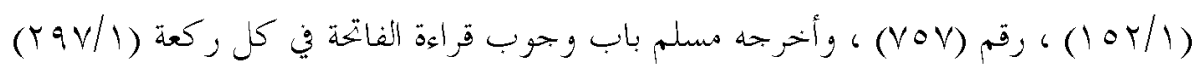
.

\{

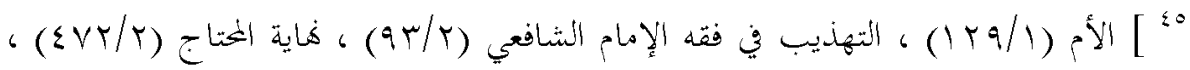

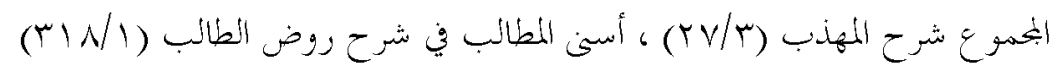

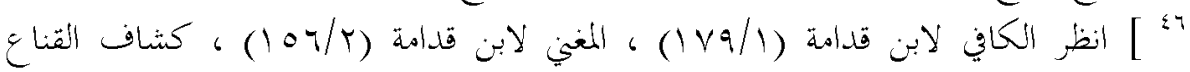

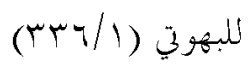

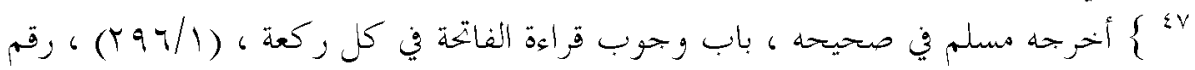

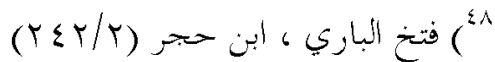

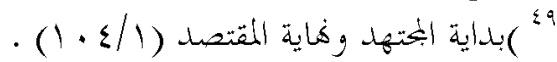

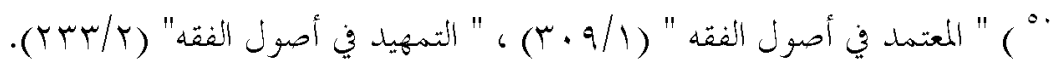

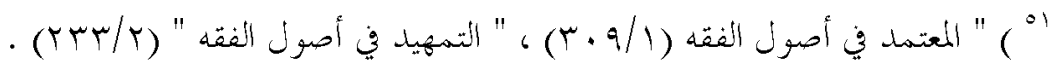

